Supporting information for:

\title{
An Improved Chemo-Enzymatic Synthesis of 1- $\beta$-O-Acyl Glucuronides: Highly Chemoselective Enzymatic Removal of the Protecting Groups from the Corresponding Methyl Acetyl Derivatives
}

\section{Akiko Baba and Tadao Yoshioka*}

List of Contents

1. $\quad{ }^{1} \mathrm{H}$ NMR and ${ }^{13} \mathrm{C}$ NMR for compound 3a

Page number

2. $\quad{ }^{1} \mathrm{H}$ NMR and ${ }^{13} \mathrm{C}$ NMR for compound $\mathbf{3 b}$

3. ${ }^{1} \mathrm{H}$ NMR and ${ }^{13} \mathrm{C}$ NMR for compound 3c

4. $\quad{ }^{1} \mathrm{H}$ NMR and ${ }^{13} \mathrm{C}$ NMR for compound 3d

5. ${ }^{1} \mathrm{H}$ NMR and ${ }^{13} \mathrm{C}$ NMR for compound $3 \mathbf{e}$

6. ${ }^{1} \mathrm{H}$ NMR and ${ }^{13} \mathrm{C}$ NMR for compound (2R)-3e S6

7. ${ }^{1} \mathrm{H}$ NMR and ${ }^{13} \mathrm{C}$ NMR for compound (2S)-3e S7

8. ${ }^{1} \mathrm{H}$ NMR and ${ }^{13} \mathrm{C}$ NMR for compound $3 \mathbf{f}$ S8

9. ${ }^{1} \mathrm{H}$ NMR and ${ }^{13} \mathrm{C}$ NMR for compound $\mathbf{4 d}$ S9

10. ${ }^{1} \mathrm{H}$ NMR and ${ }^{13} \mathrm{C}$ NMR for compound $4 \mathbf{e}$ S10

11. ${ }^{1} \mathrm{H}$ NMR and ${ }^{13} \mathrm{C}$ NMR for compound 5a S11

12. ${ }^{1} \mathrm{H}$ NMR and ${ }^{13} \mathrm{C}$ NMR for compound $5 \mathbf{b}$ S12

13. ${ }^{1} \mathrm{H}$ NMR and ${ }^{13} \mathrm{C}$ NMR for compound 5c S13

14. ${ }^{1} \mathrm{H}$ NMR and ${ }^{13} \mathrm{C}$ NMR for compound $5 \mathbf{d}$ S14

15. ${ }^{1} \mathrm{H}$ NMR and ${ }^{13} \mathrm{C}$ NMR for compound (2R)-5e S15

16. ${ }^{1} \mathrm{H}$ NMR and ${ }^{13} \mathrm{C}$ NMR for compound (2S)-5e S16

17. ${ }^{1} \mathrm{H}$ NMR and ${ }^{13} \mathrm{C}$ NMR for compound $\mathbf{5 f}$ S17

18. ${ }^{1} \mathrm{H}$ NMR and ${ }^{13} \mathrm{C}$ NMR for compound 6 S18

19. ${ }^{1} \mathrm{H}$ NMR and ${ }^{13} \mathrm{C}$ NMR for compound 7

S19

S20

${ }^{1} \mathrm{H}$ NMR (400 MHz) and ${ }^{13} \mathrm{C}$ NMR (100 MHz) were recorded at ambient temperature $\left(23{ }^{\circ} \mathrm{C}\right.$ ), except for compound $3 \mathbf{d}$ whose ${ }^{1} \mathrm{H}$ and ${ }^{13} \mathrm{C}$ NMR were recorded at $270 \mathrm{MHz}$ and $68 \mathrm{MHz}$, respectively. The chemical shifts measured in either $\mathrm{D}_{6}$-DMSO or $\mathrm{CD}_{3} \mathrm{OD}$ are shown in ppm using the residual solvent peaks as internal standards relative to TMS. 


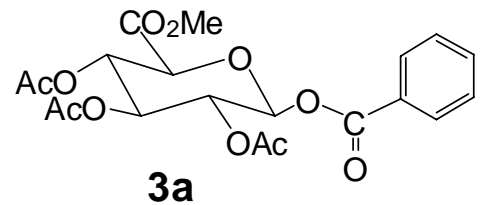

${ }^{1}$ H NMR

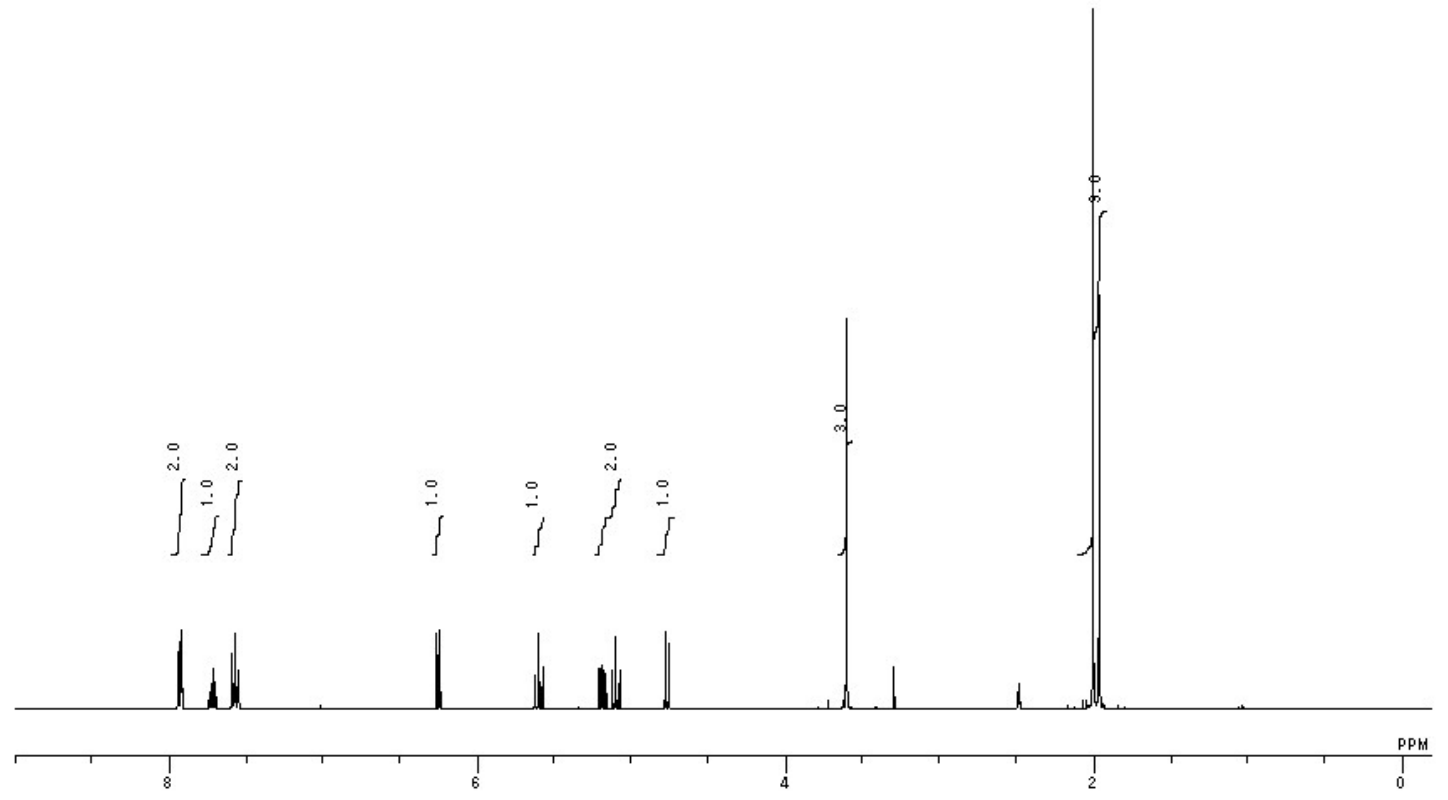

${ }^{13} \mathrm{C}$ NMR

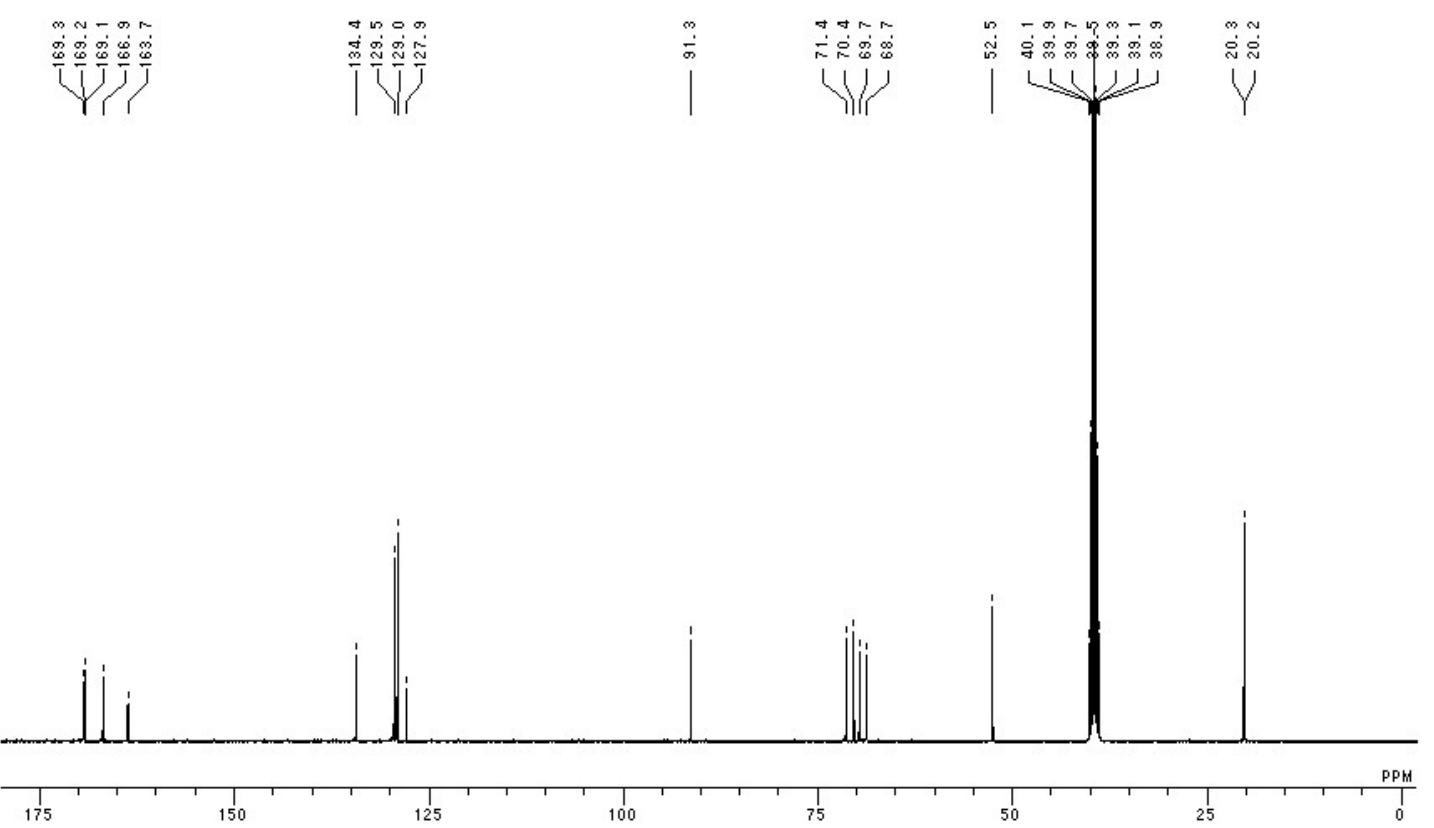




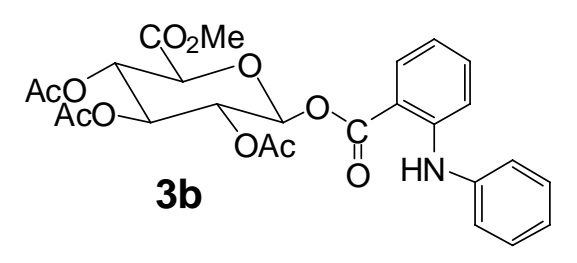

${ }^{1}$ H NMR

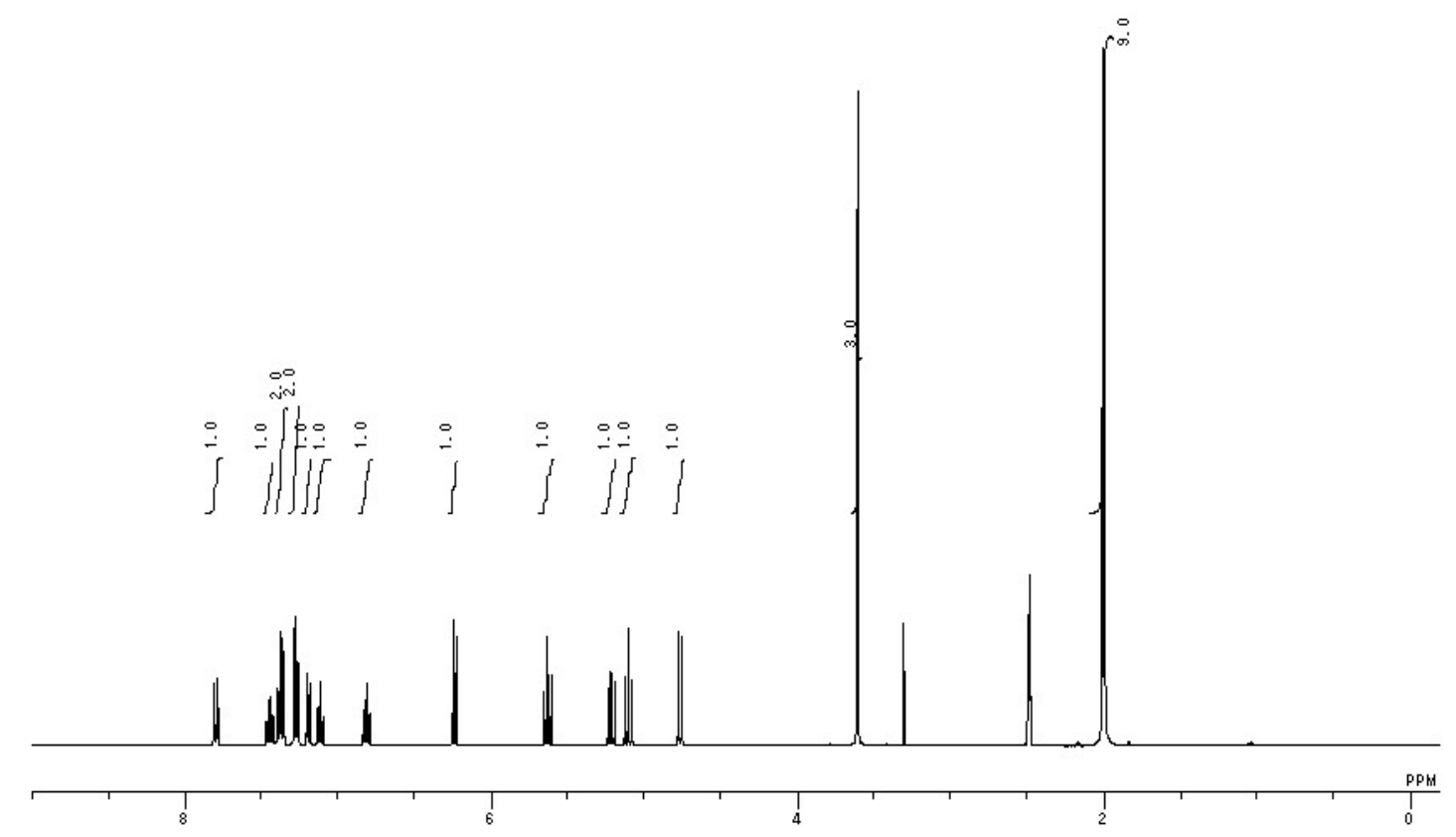

${ }^{13} \mathrm{C}$ NMR

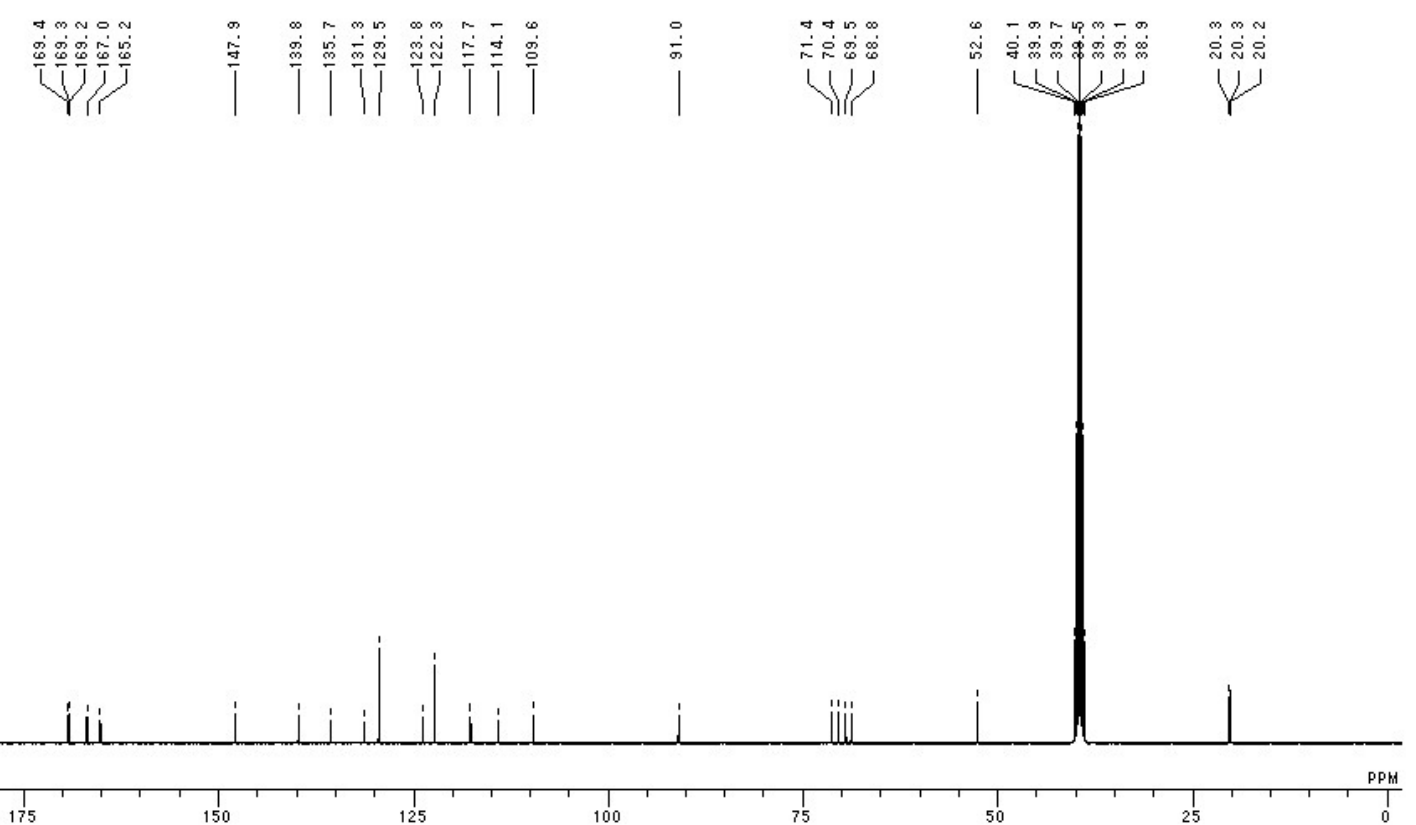




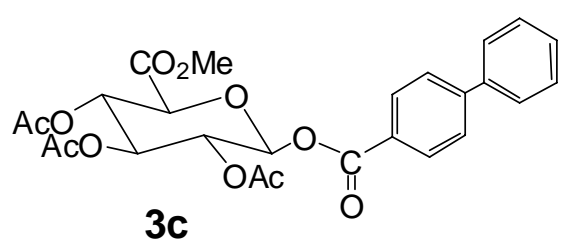

${ }^{1}$ H NMR

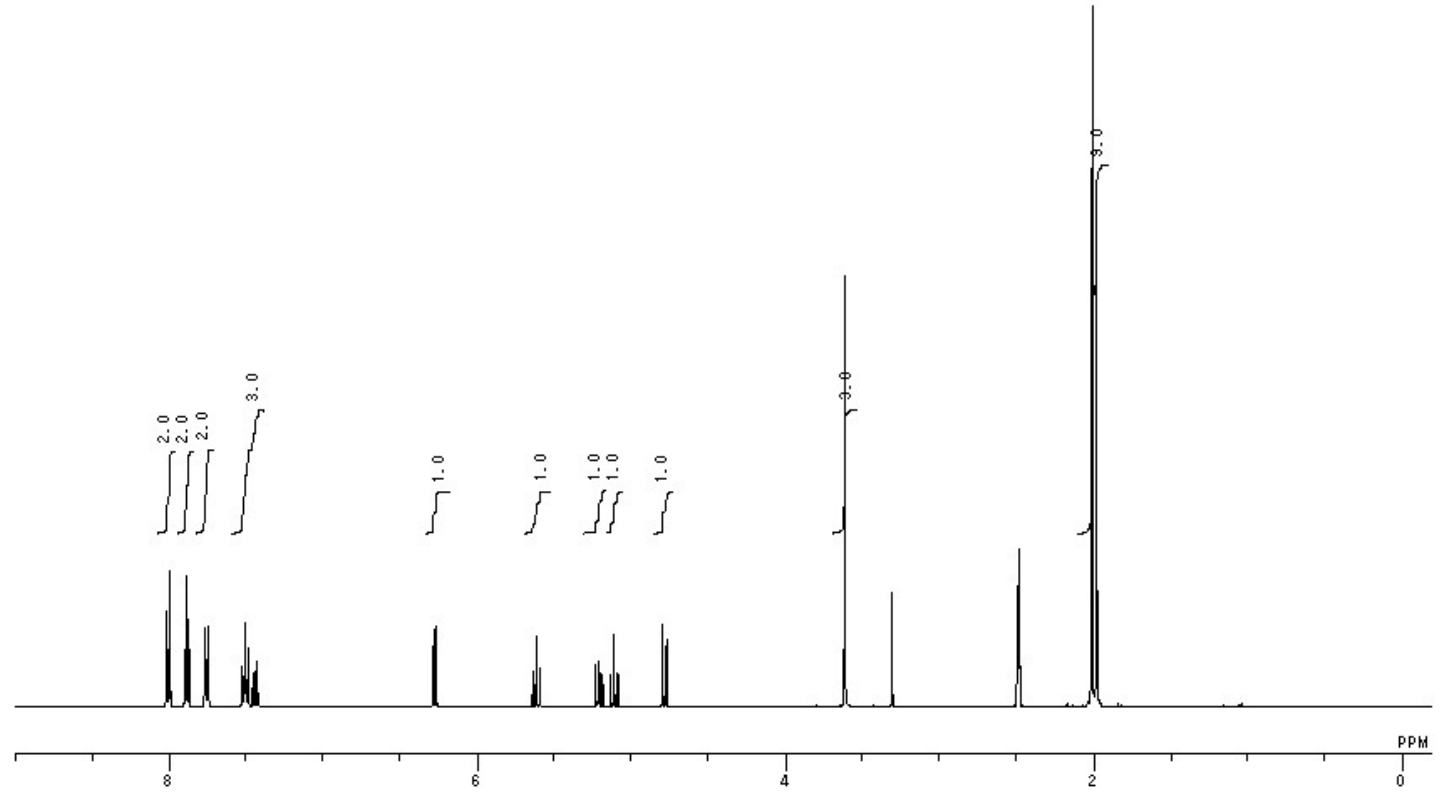

${ }^{13} \mathrm{C}$ NMR

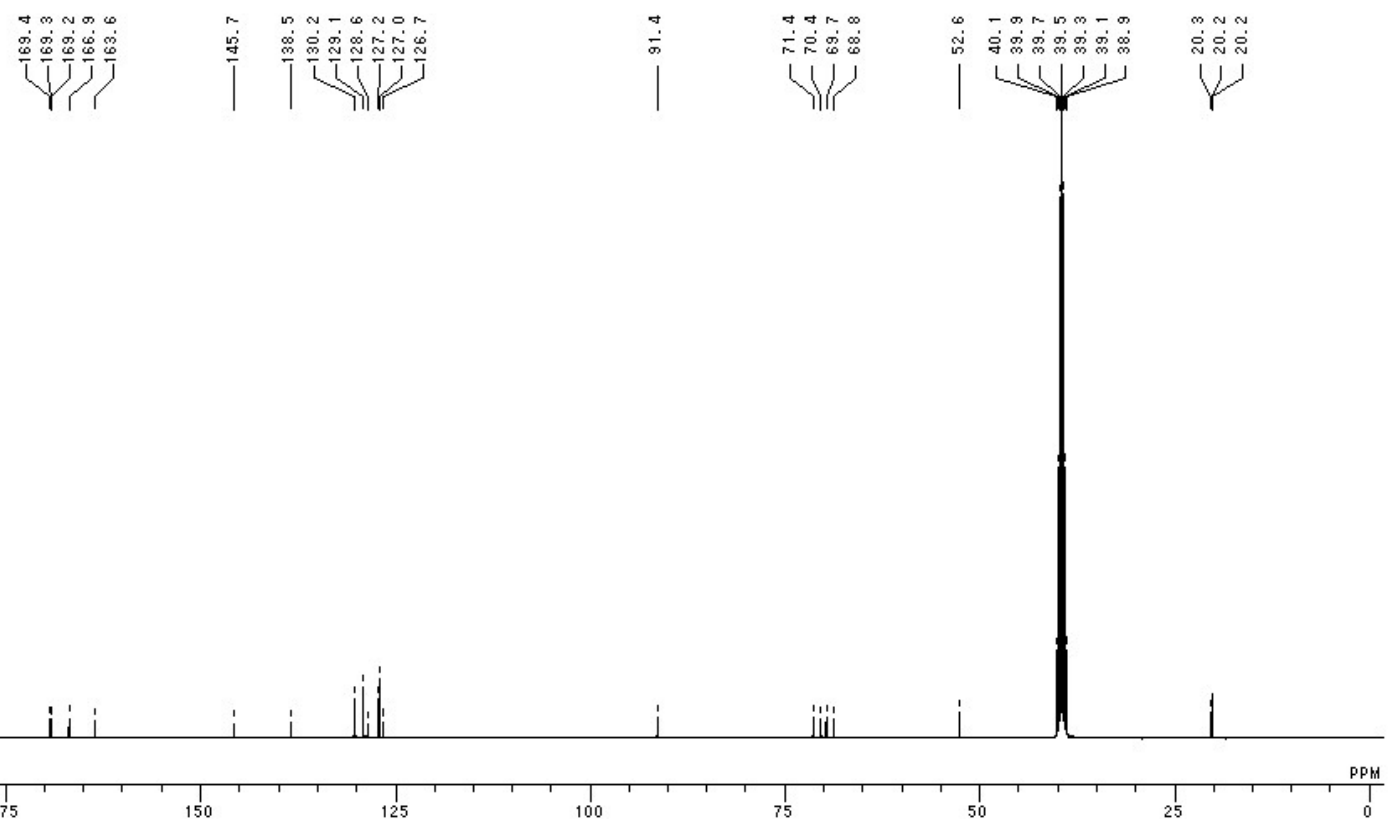




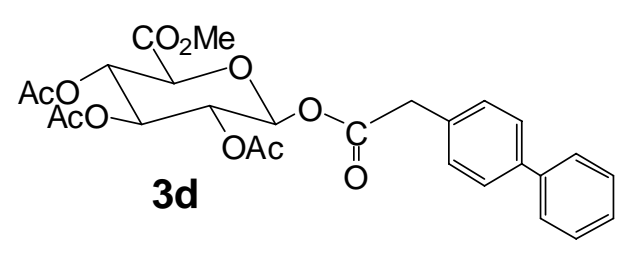

\section{${ }^{1}$ H NMR}

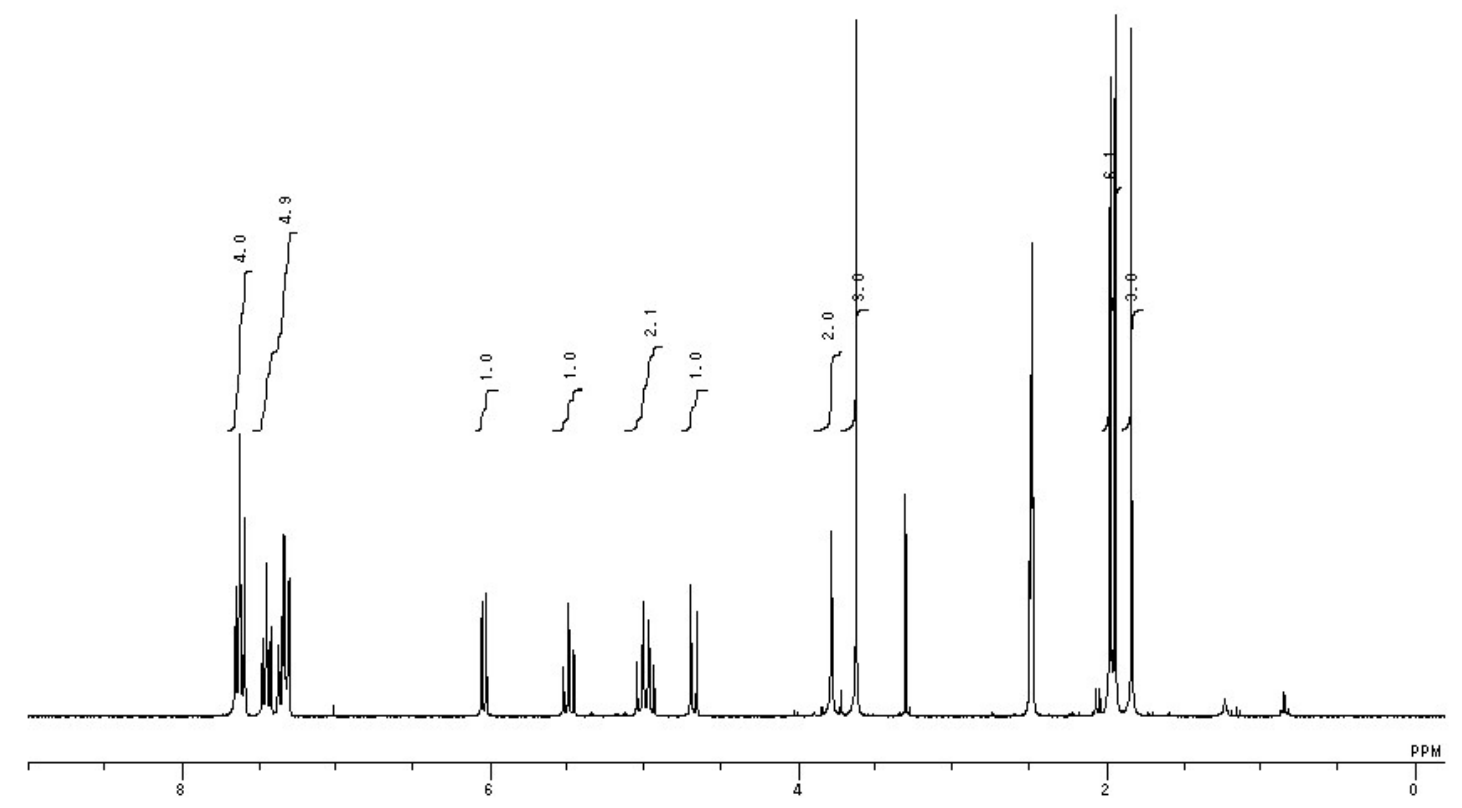

\section{${ }^{13}$ C NMR}

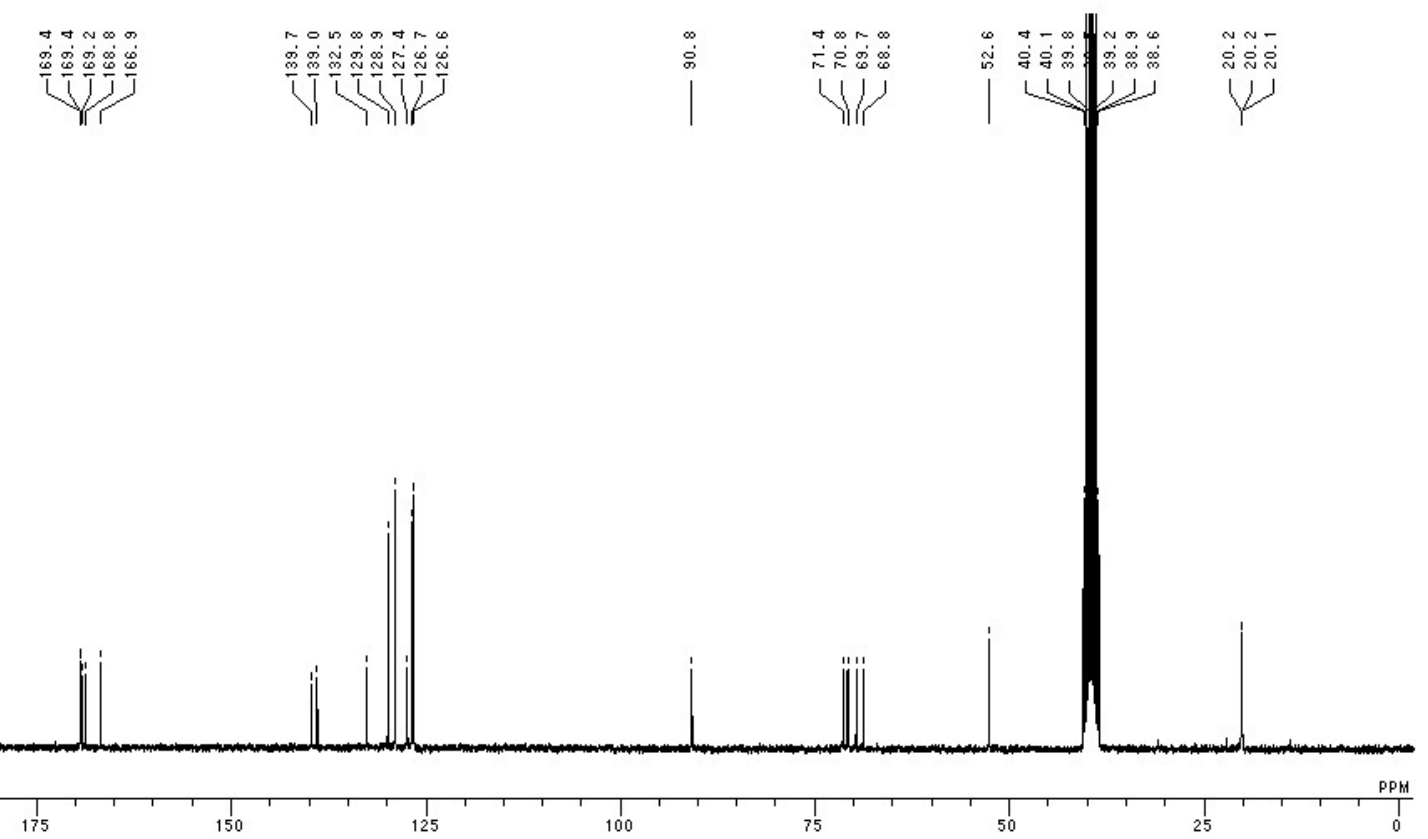




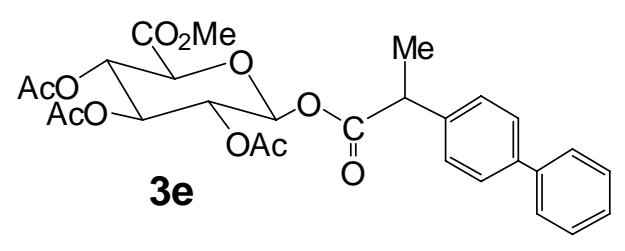

${ }^{1}$ H NMR

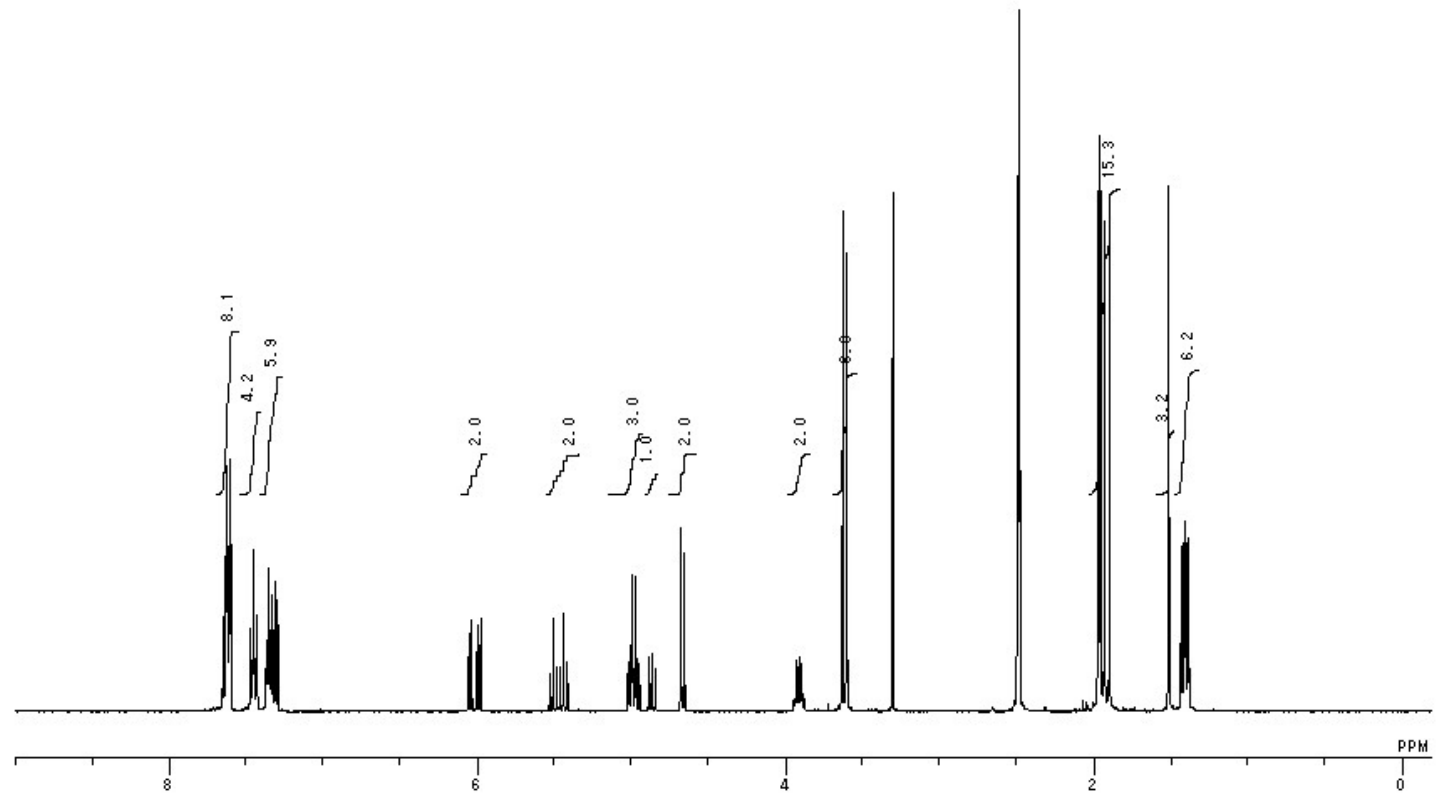

${ }^{13} \mathrm{C}$ NMR

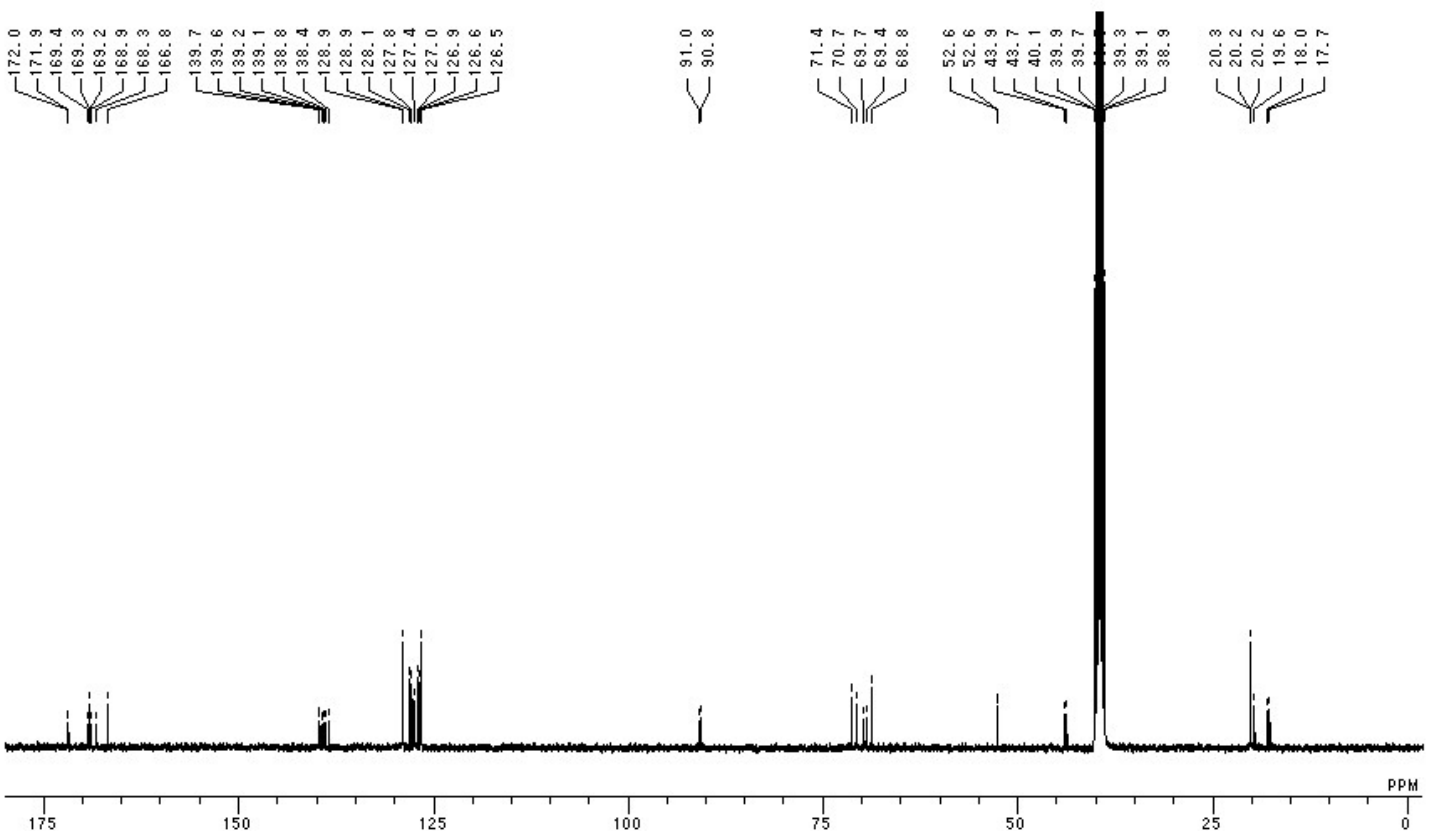




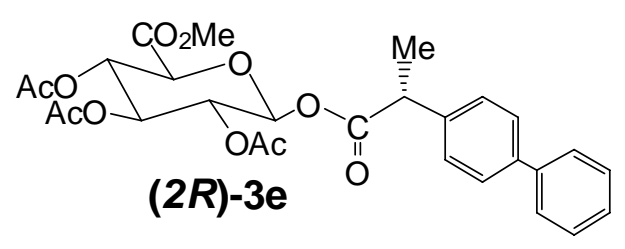

${ }^{1}$ H NMR

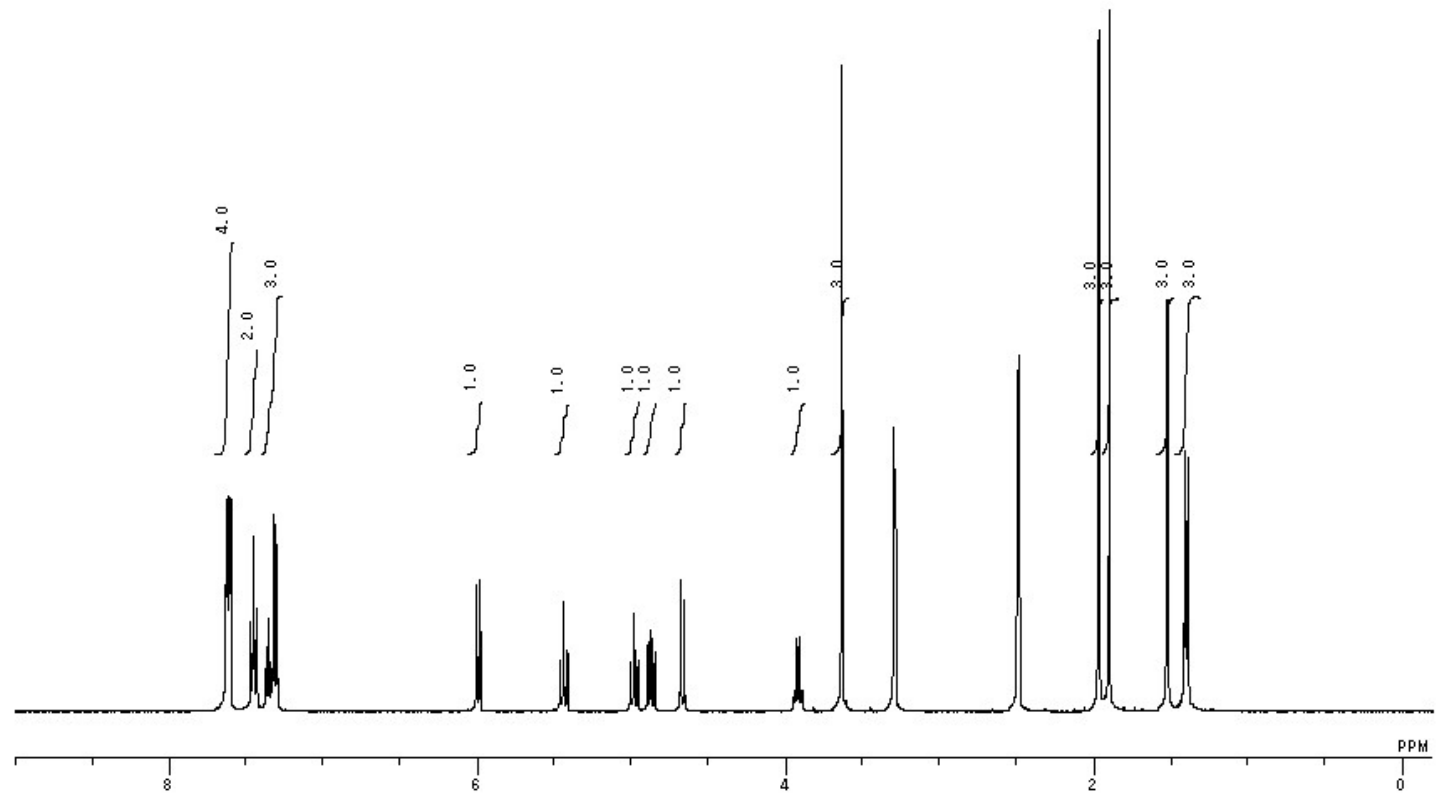

${ }^{13} \mathrm{C}$ NMR

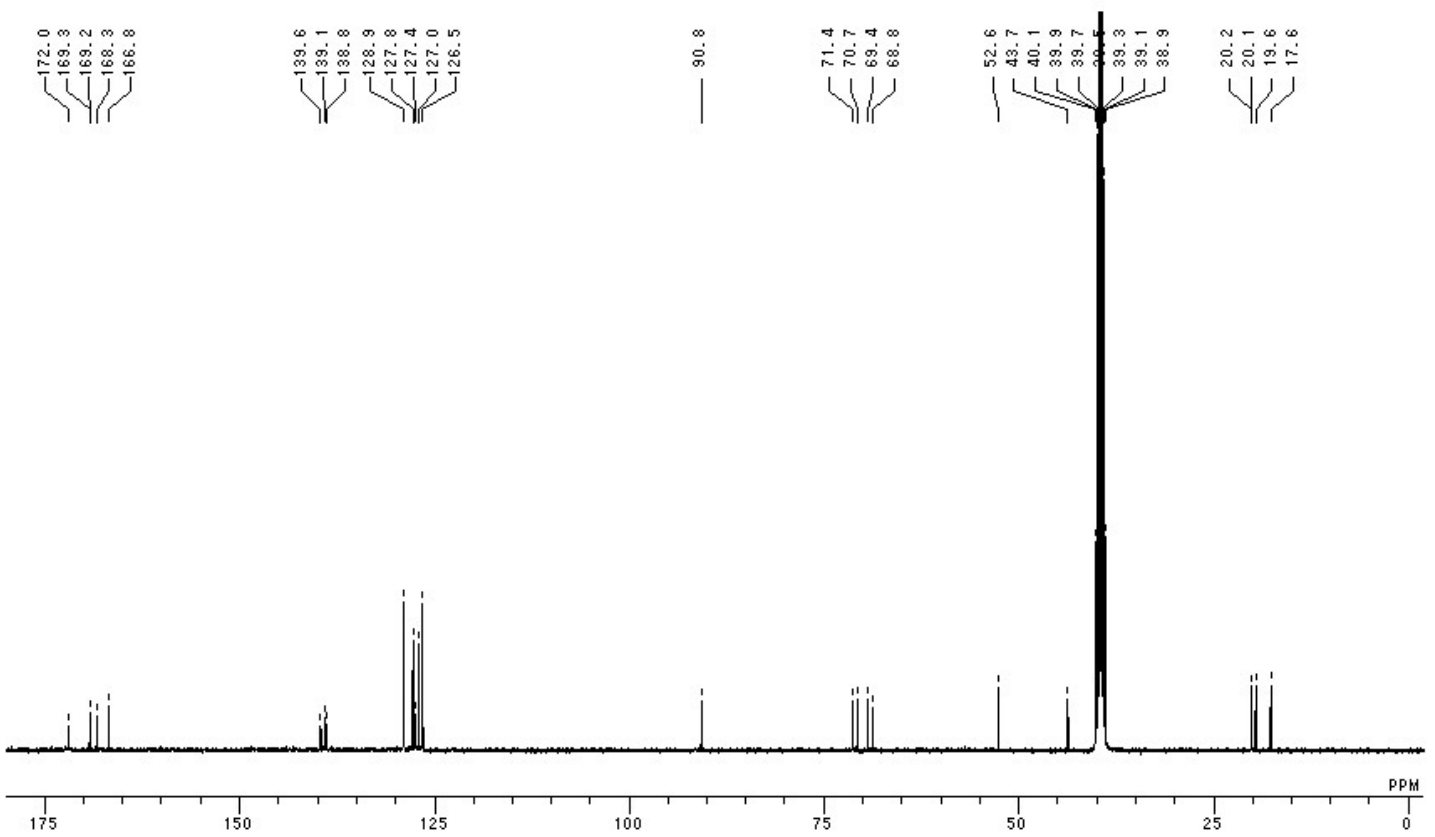




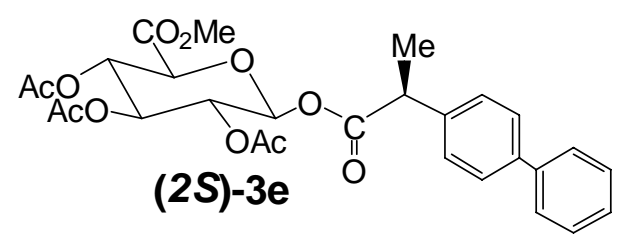

${ }^{1}$ H NMR

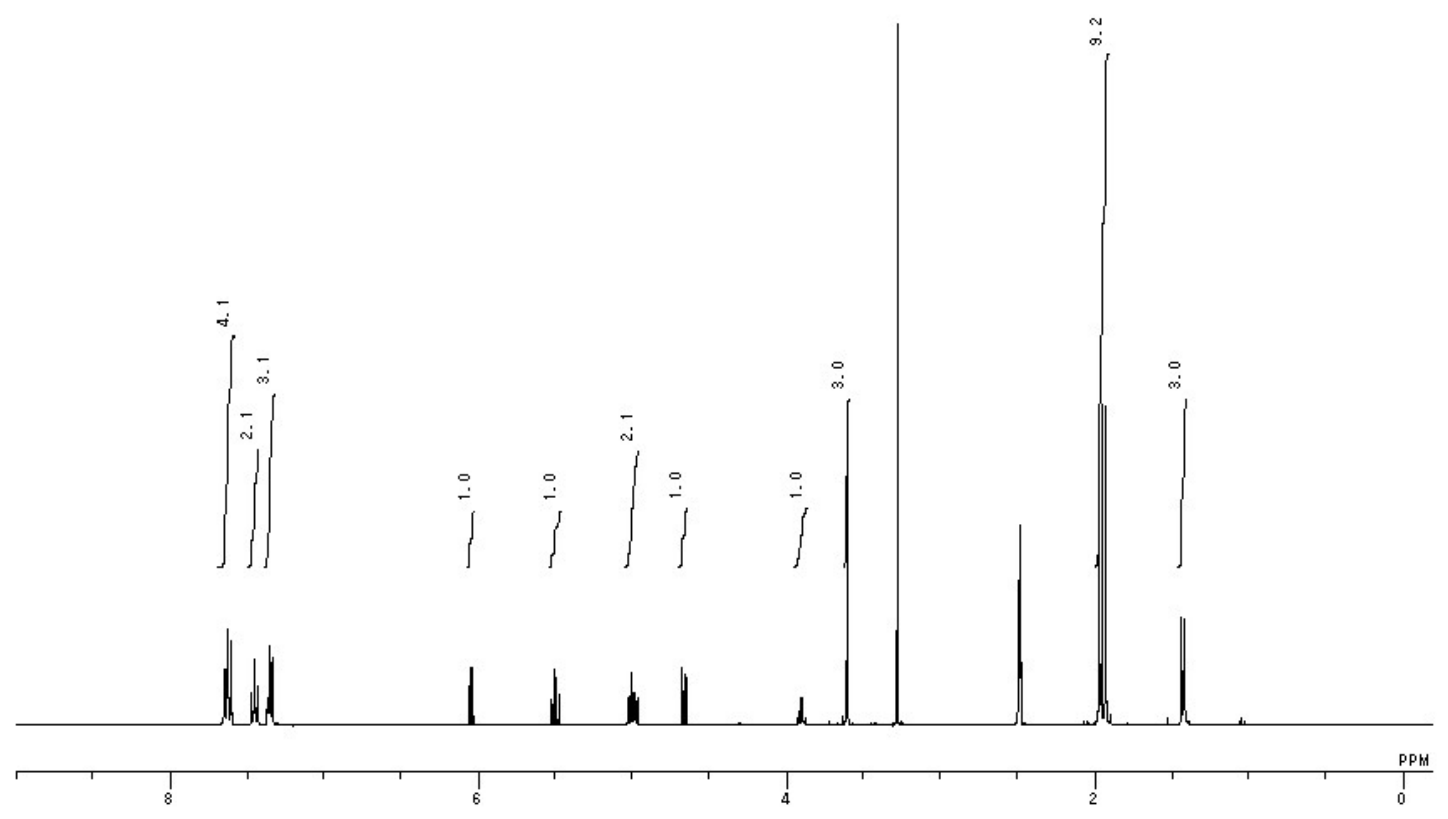

\section{${ }^{13}$ C NMR}

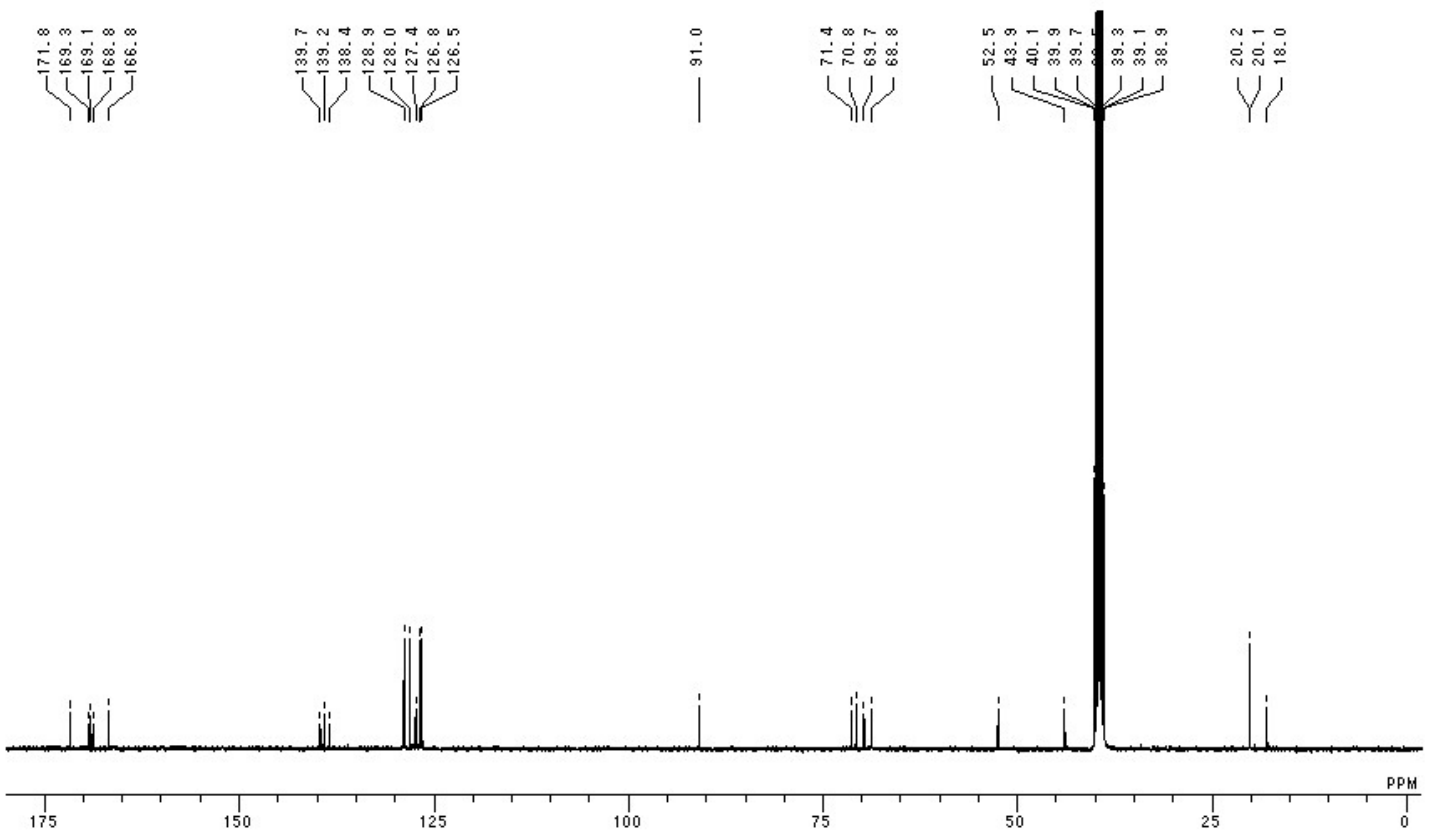




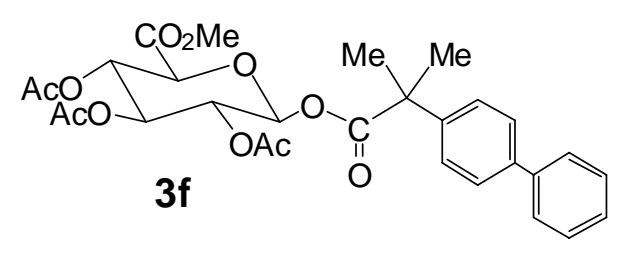

${ }^{1}$ H NMR

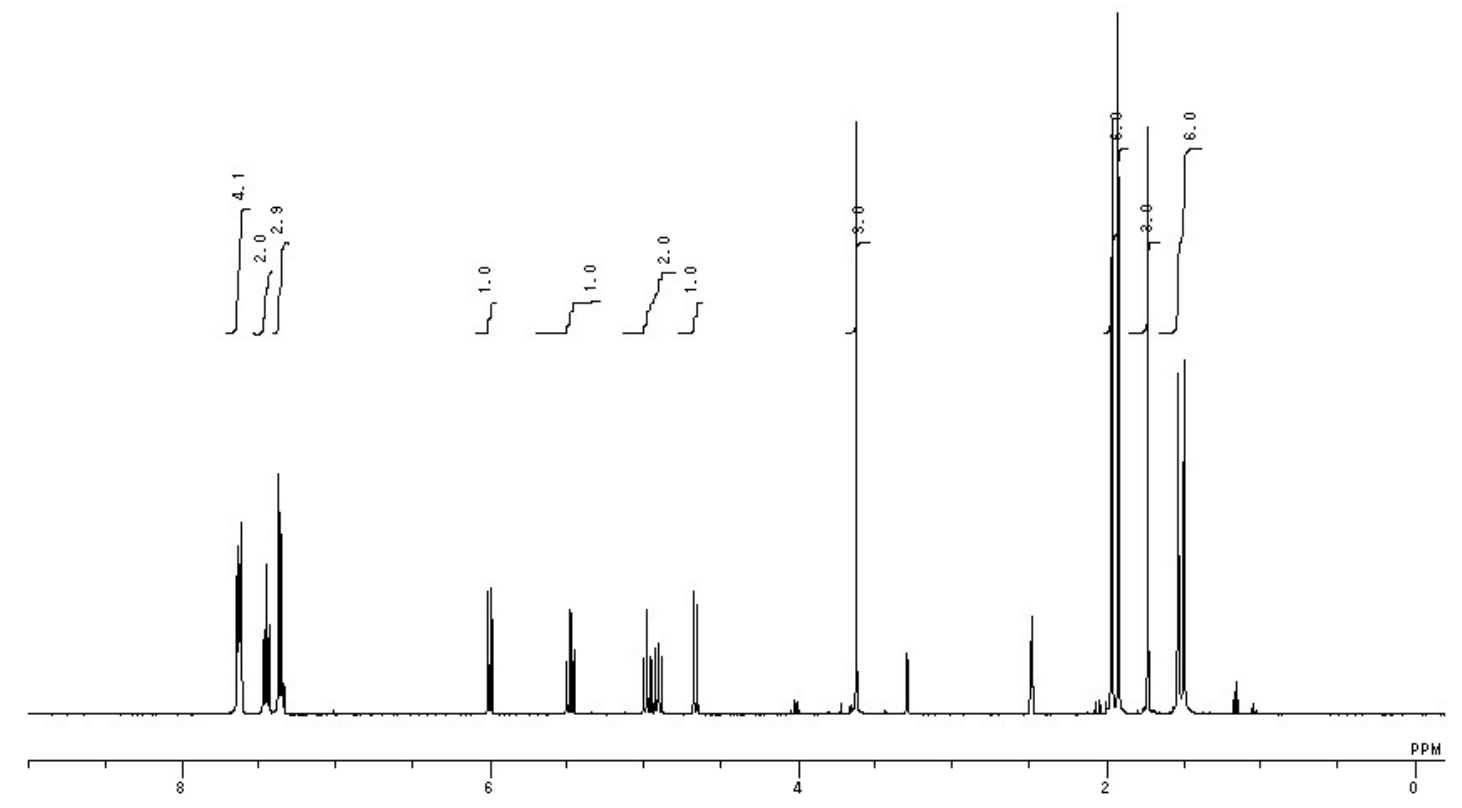

${ }^{13} \mathrm{C}$ NMR

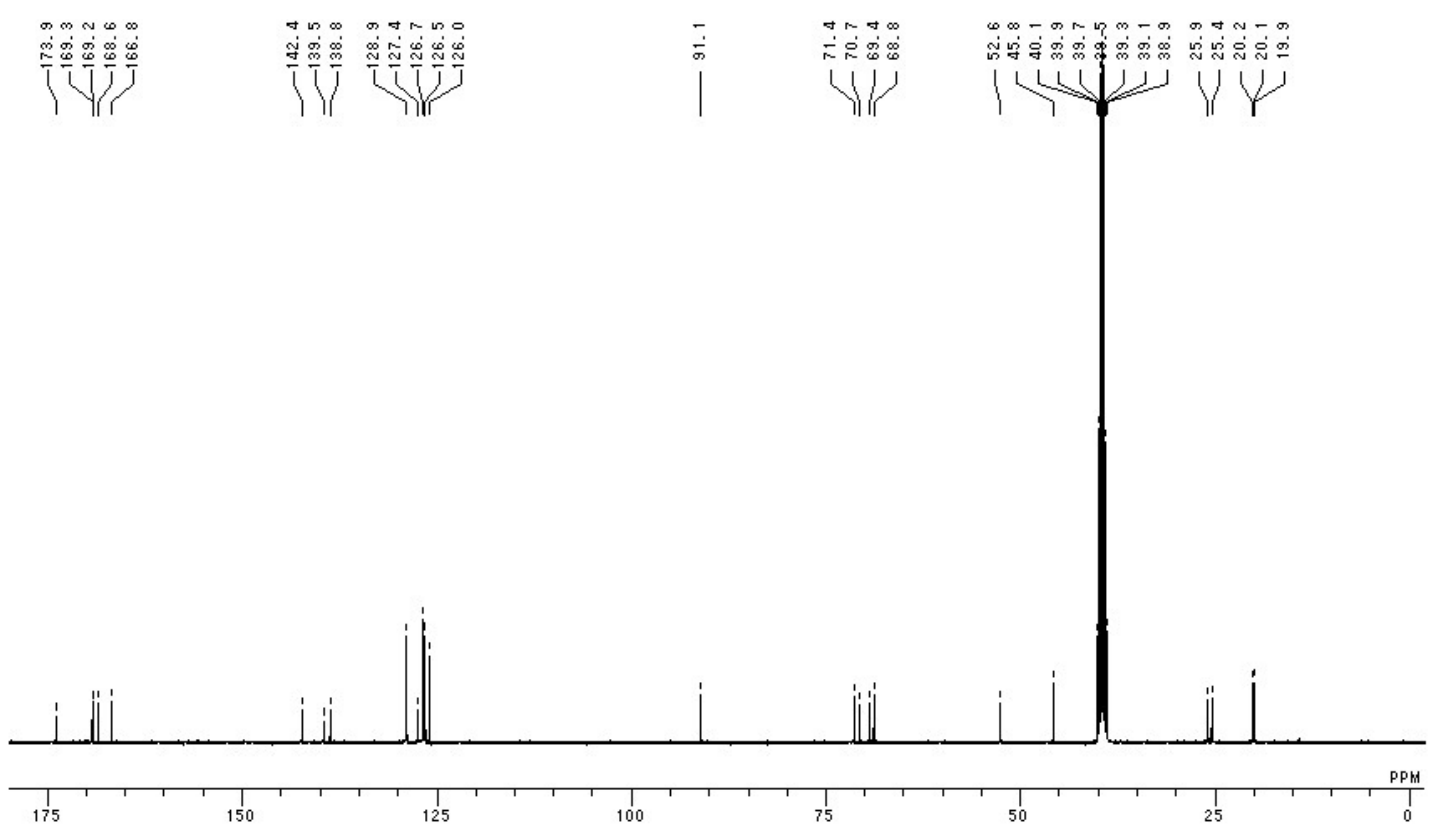




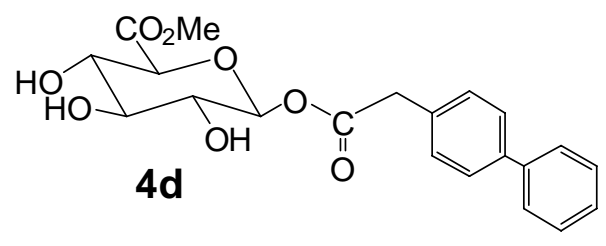

${ }^{1}$ H NMR

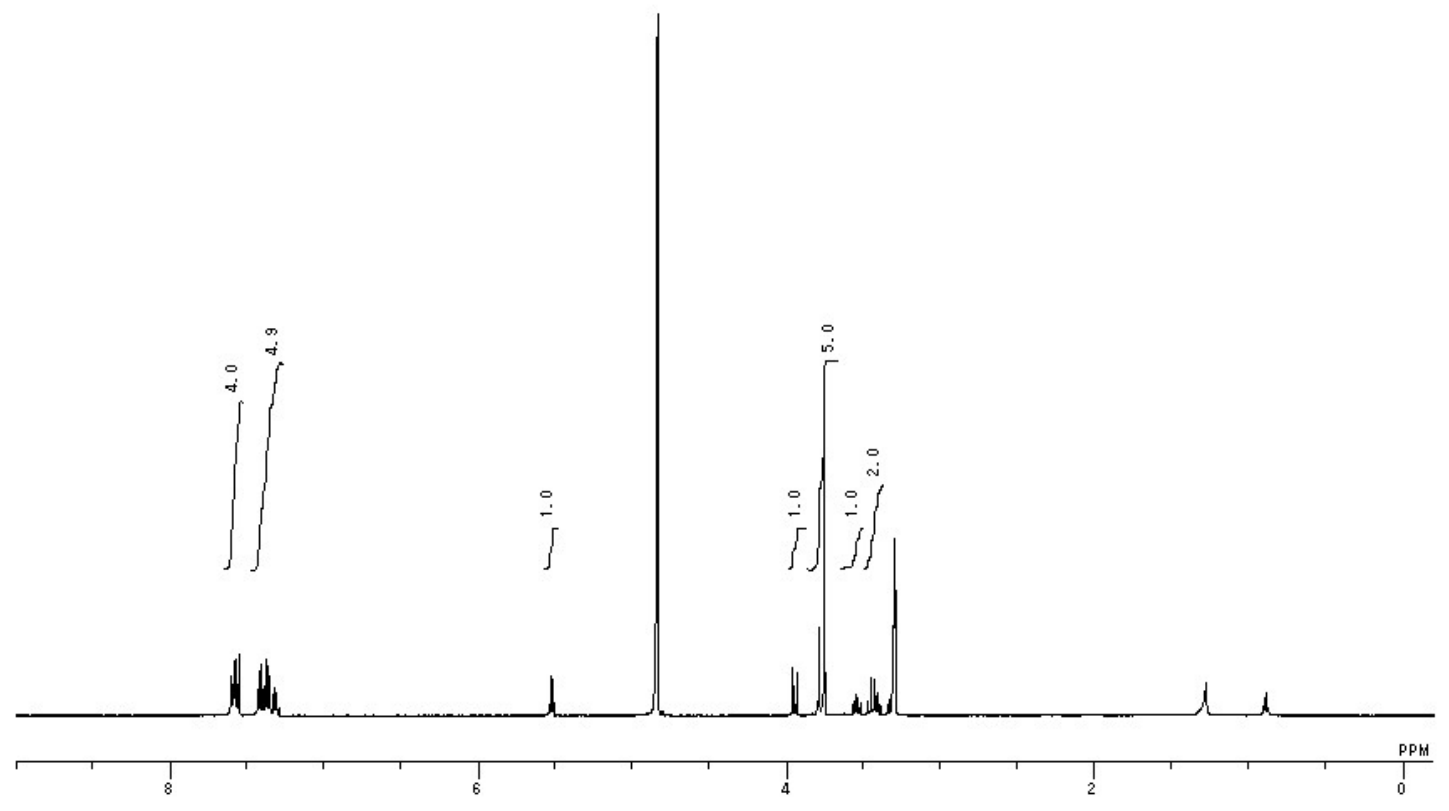

${ }^{13} \mathrm{C}$ NMR

$\sqrt{1}$

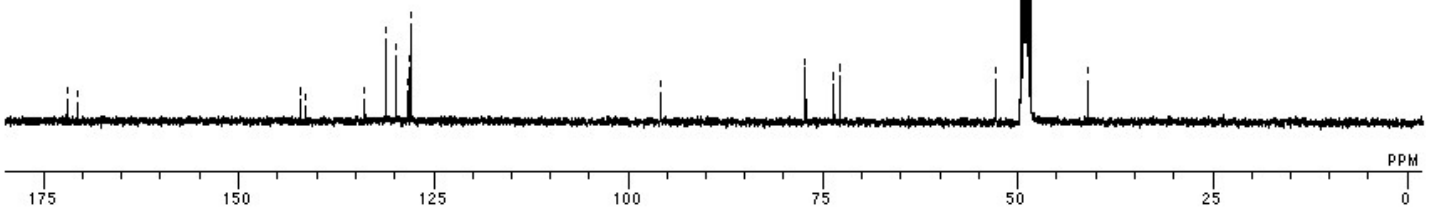




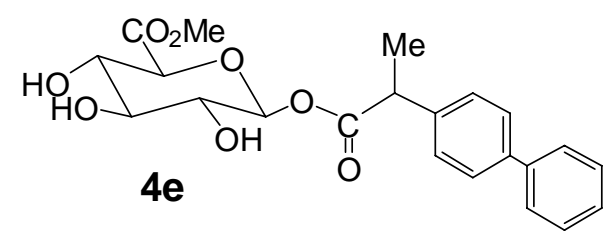

${ }^{1}$ H NMR

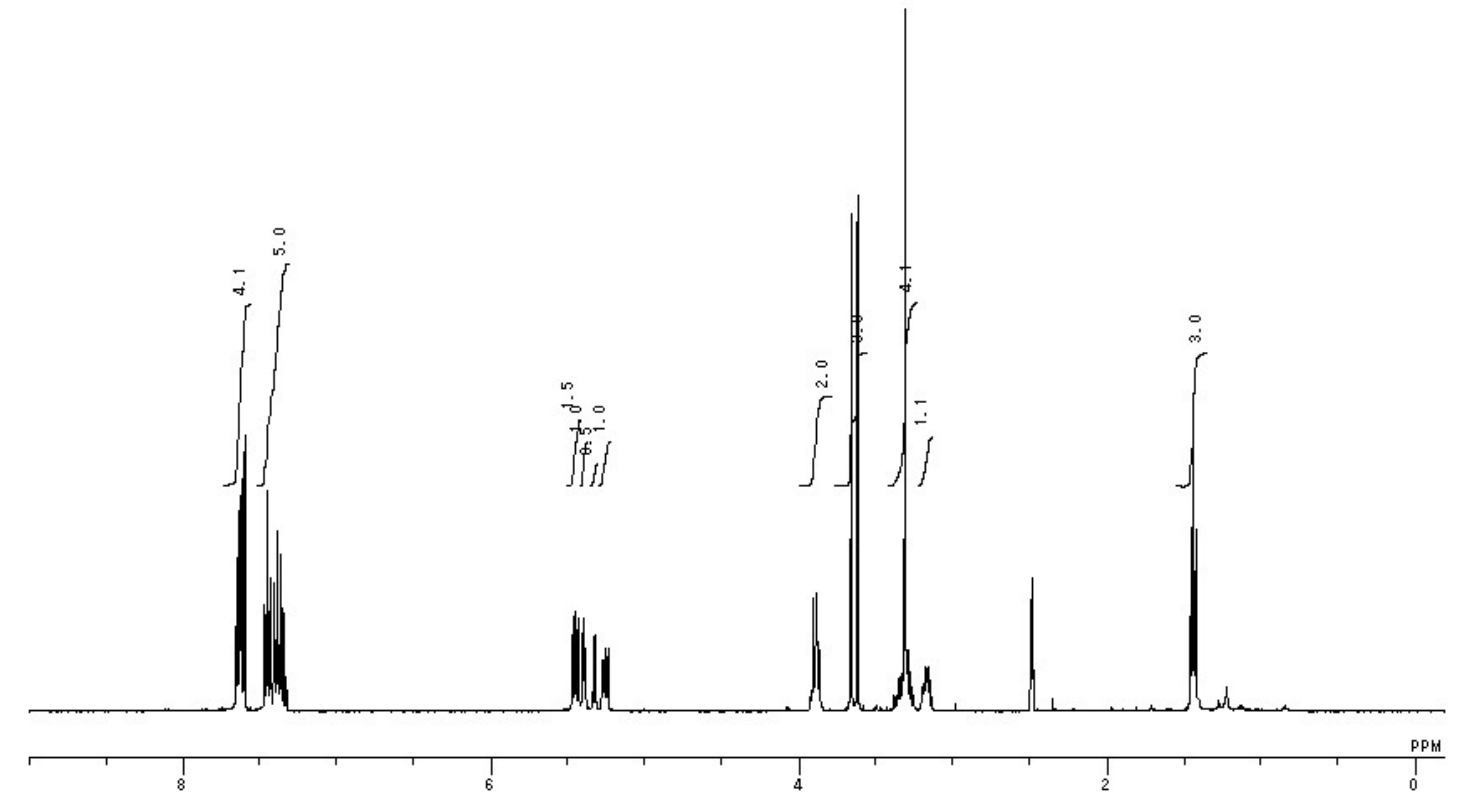

${ }^{13} \mathrm{C}$ NMR

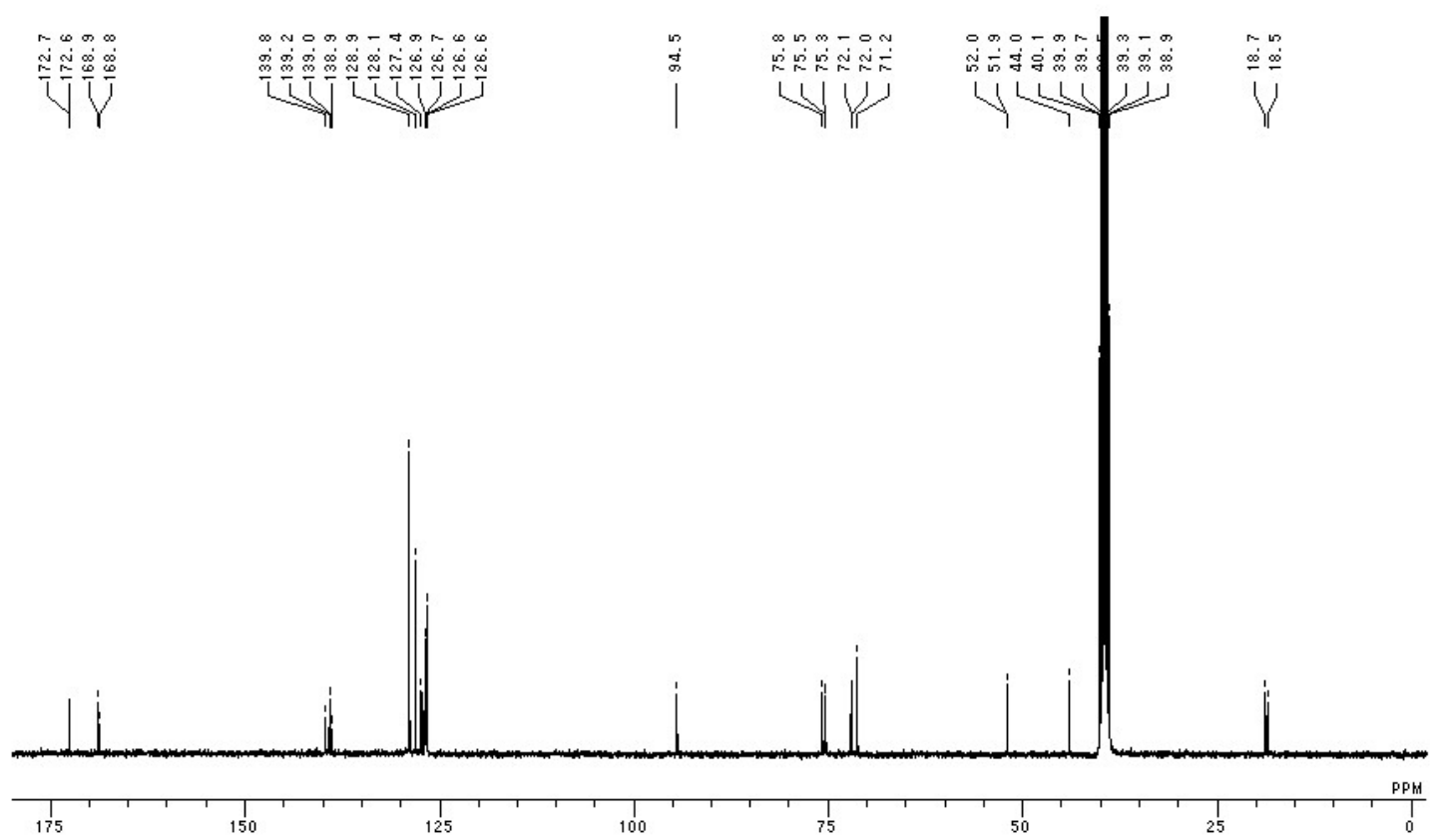




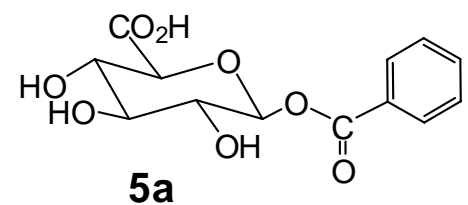

${ }^{1}$ H NMR

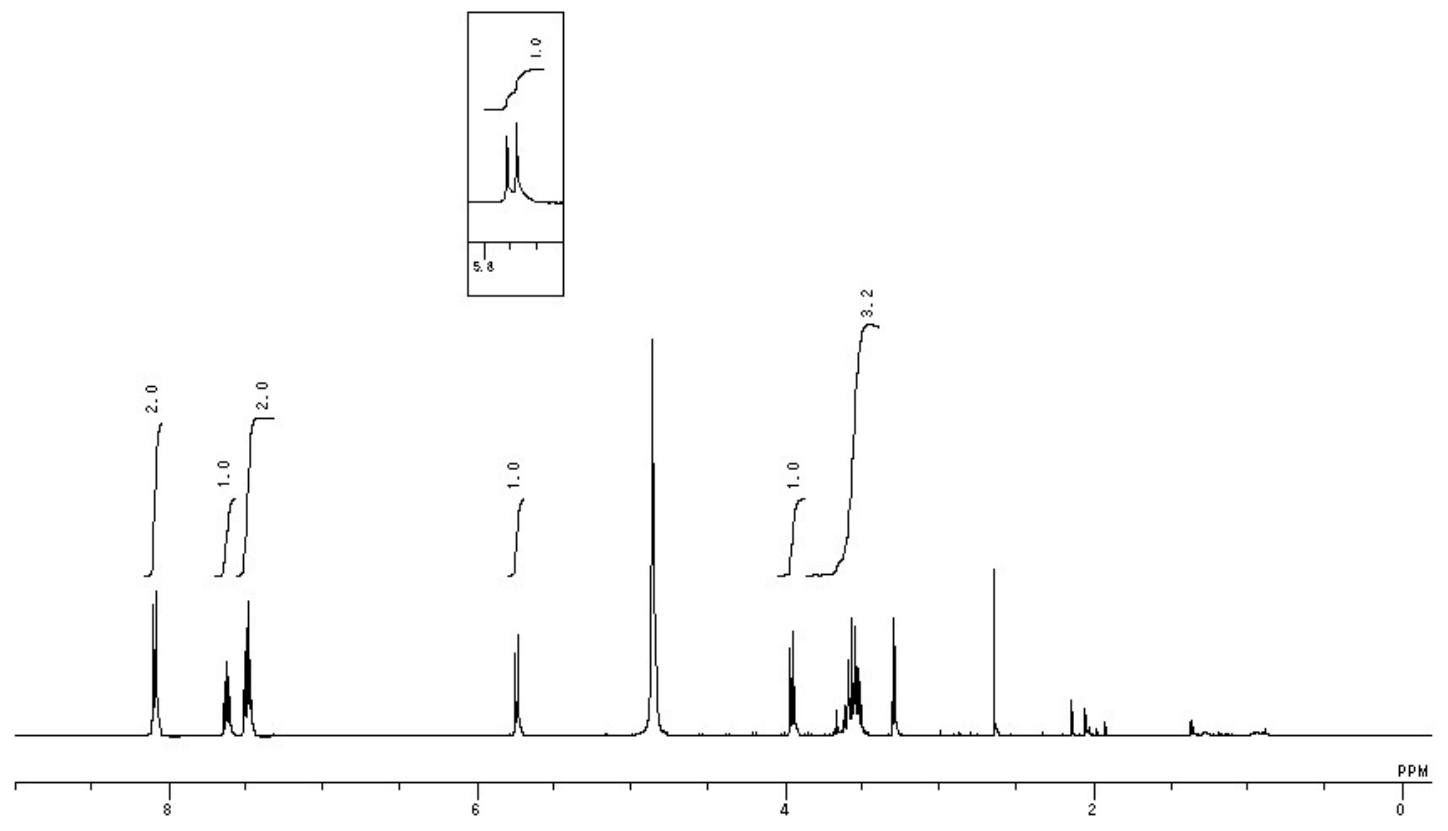

${ }^{13}$ C NMR

||

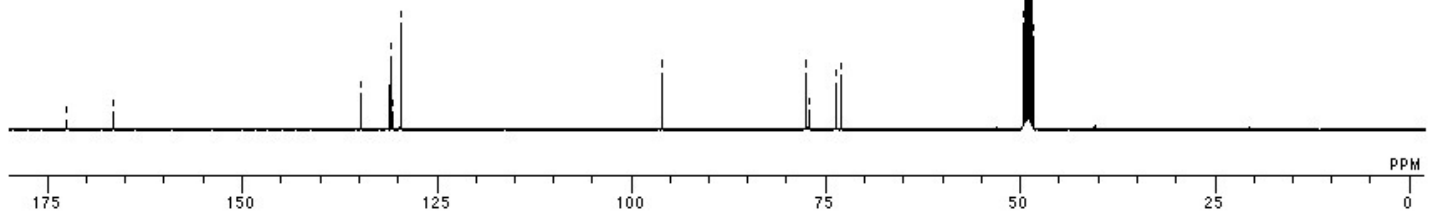




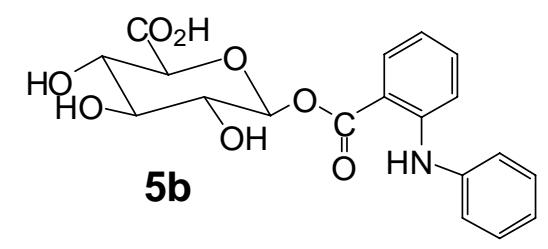

${ }^{1}$ H NMR

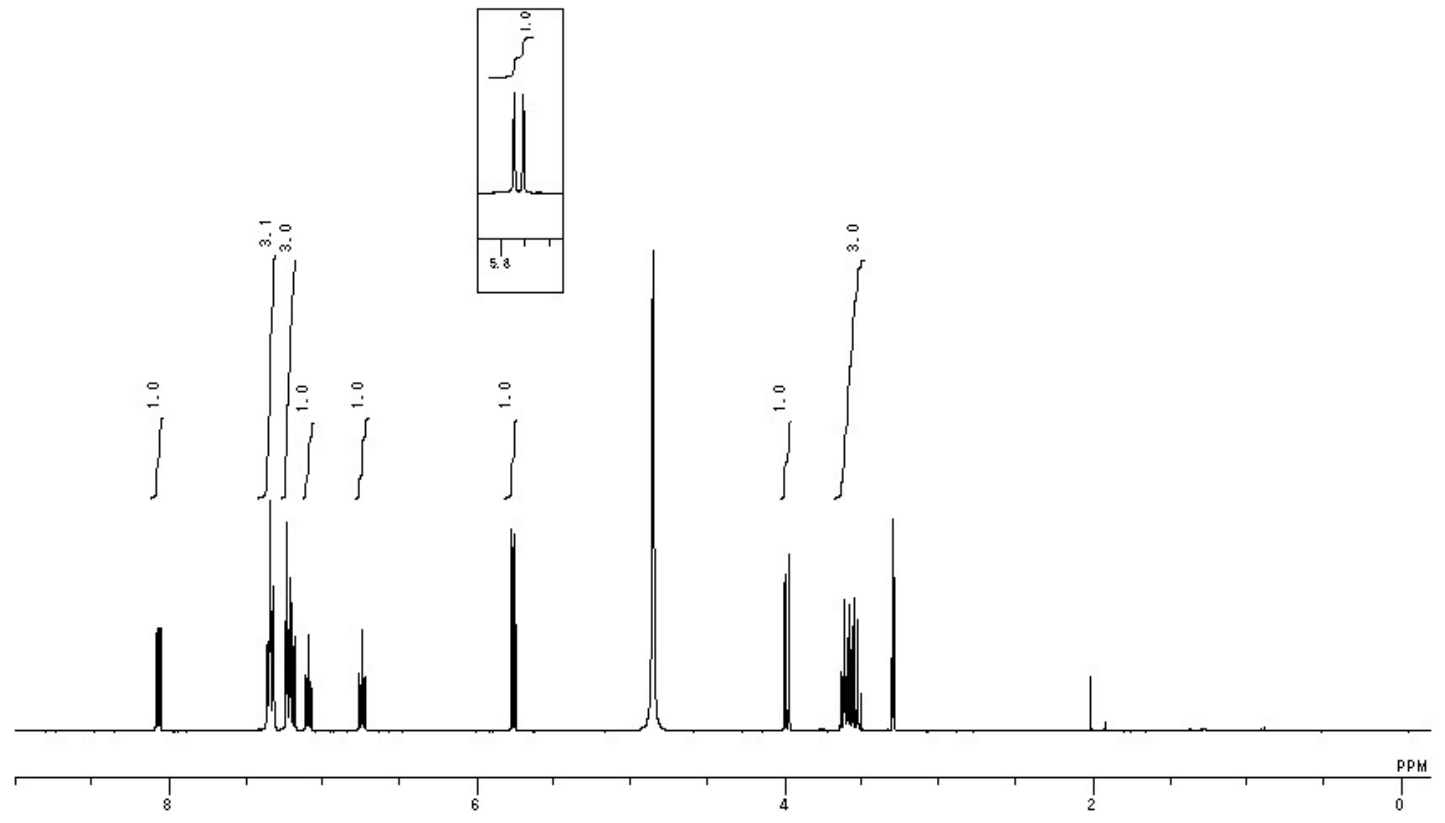

${ }^{13} \mathrm{C}$ NMR

|
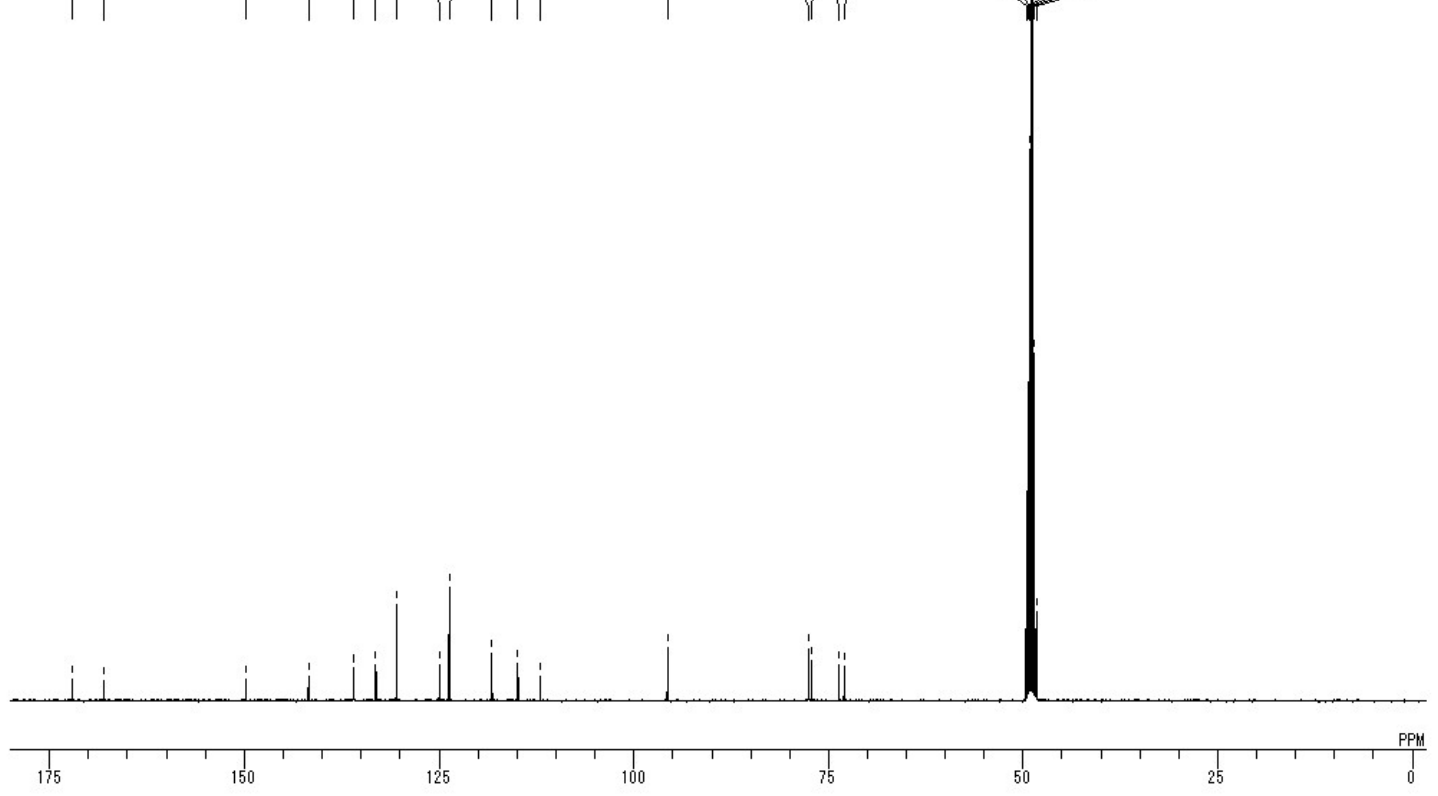


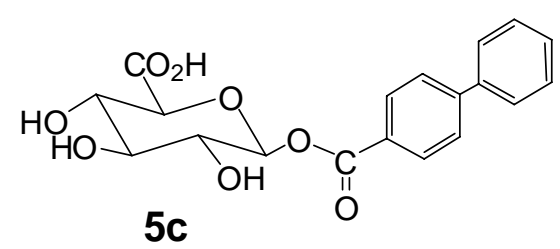

${ }^{1}$ H NMR

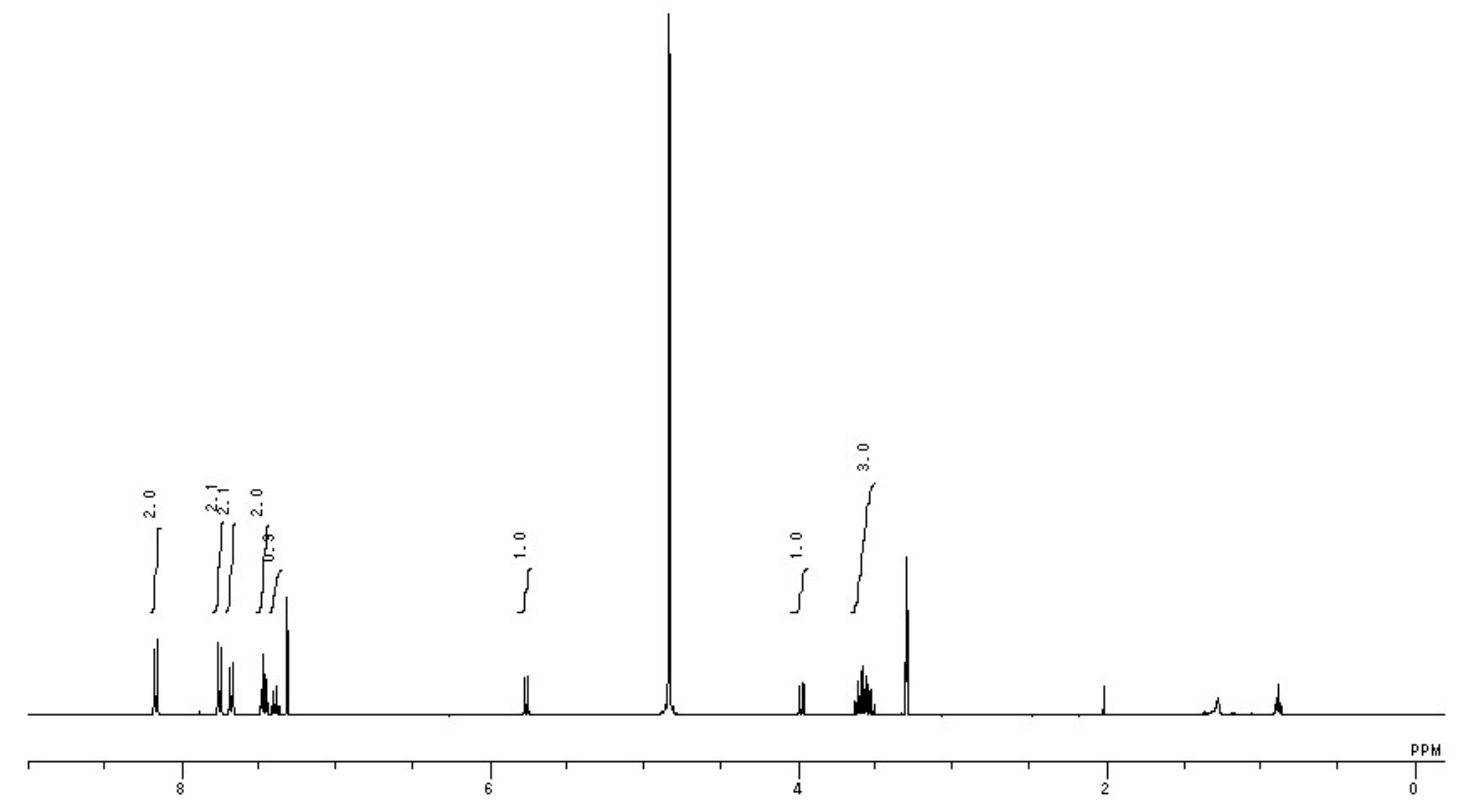

${ }^{13} \mathrm{C}$ NMR

ป⿻

(1)

$\sqrt{2}$

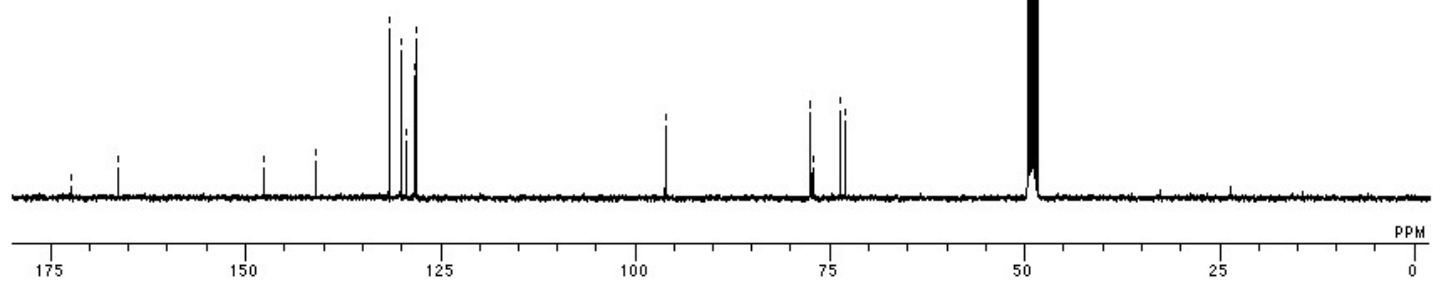




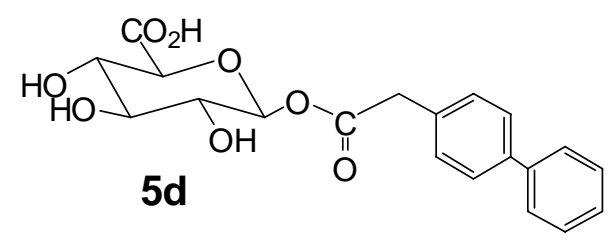

${ }^{1}$ H NMR

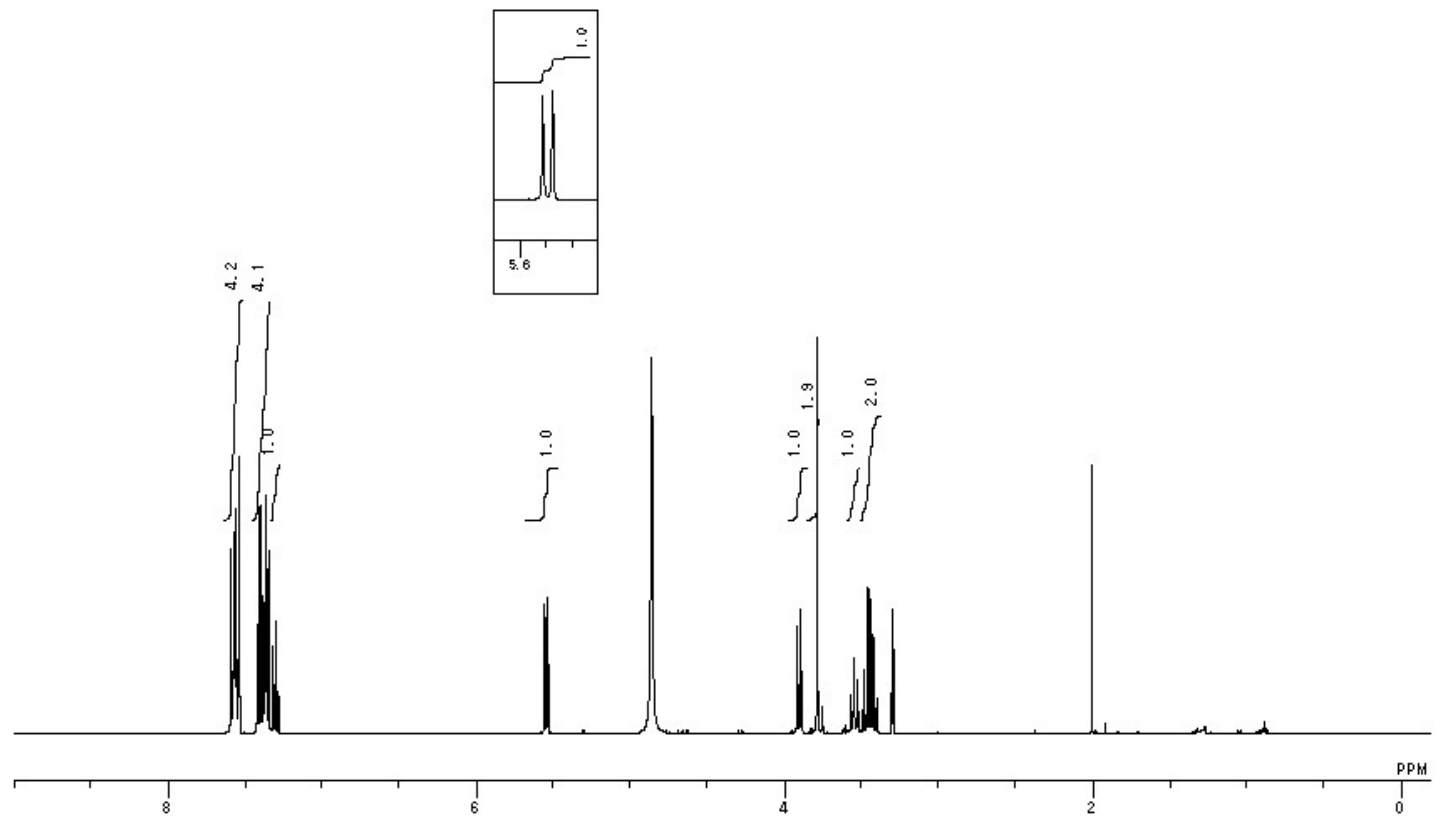

${ }^{13} \mathrm{C}$ NMR

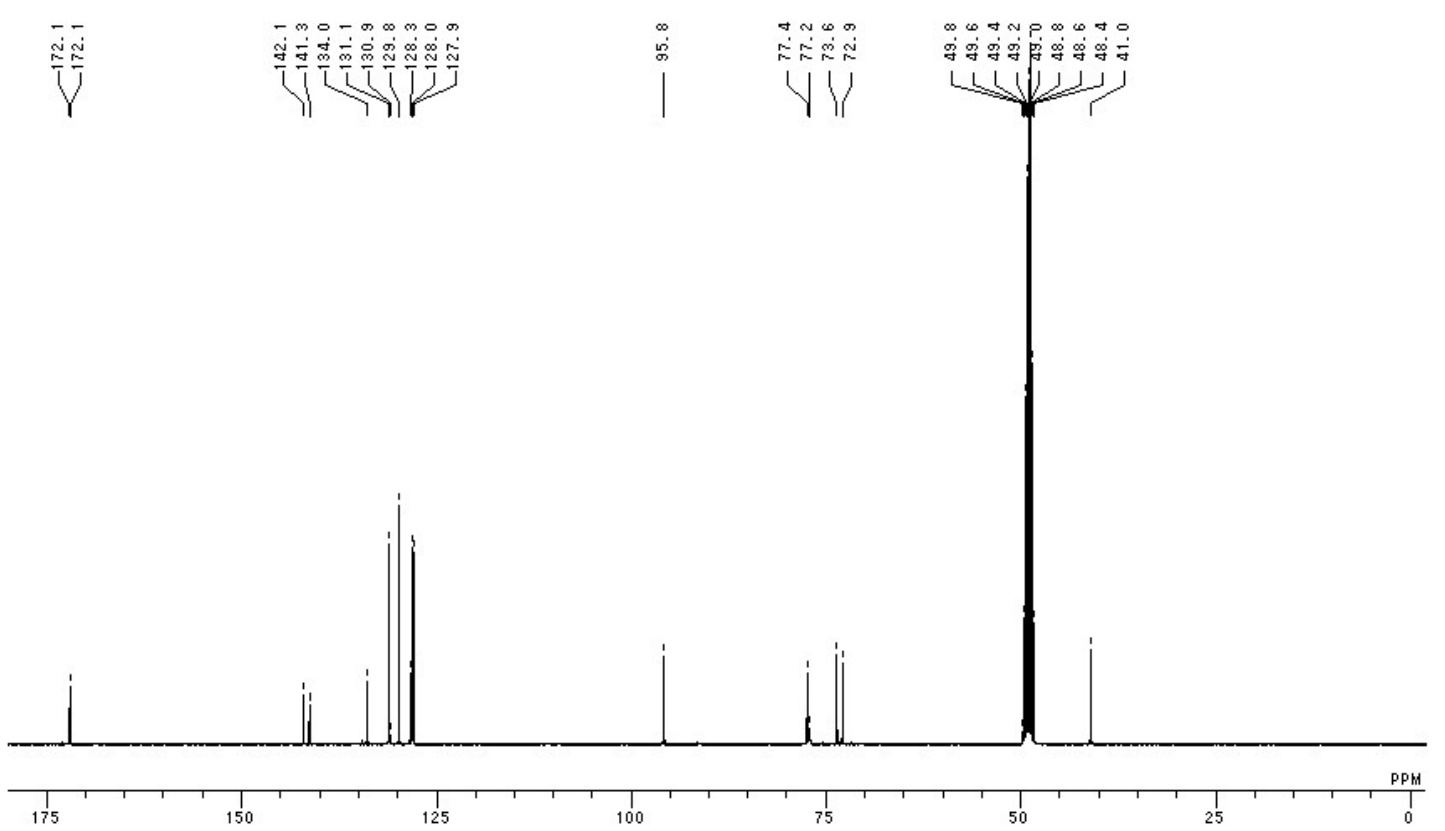




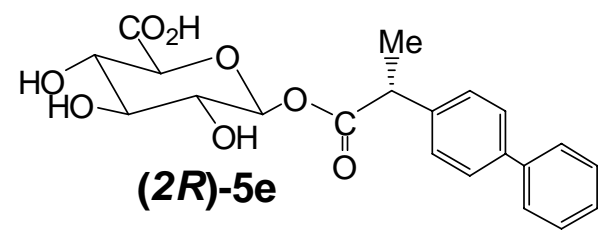

${ }^{1}$ H NMR

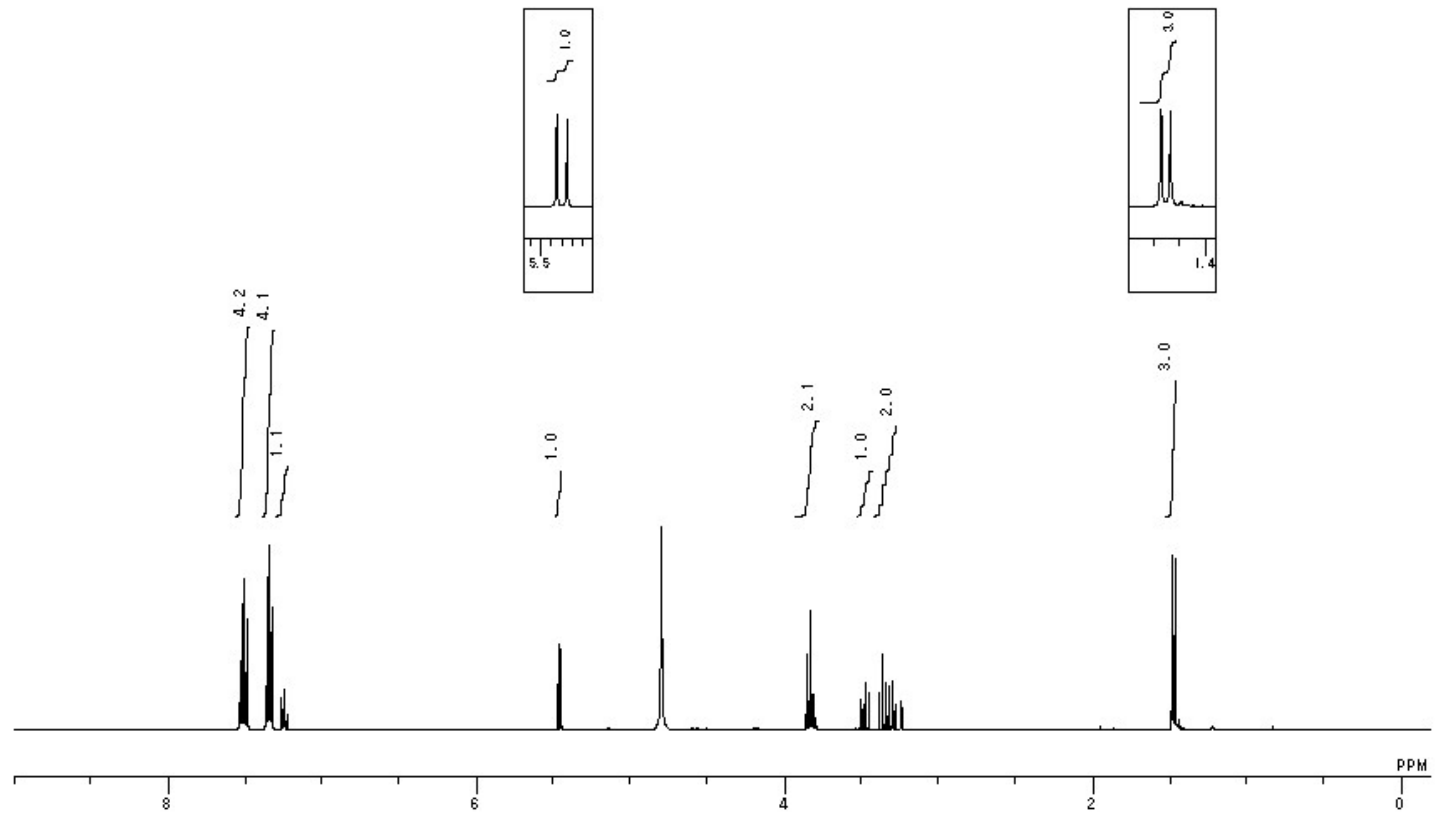

${ }^{13} \mathrm{C}$ NMR

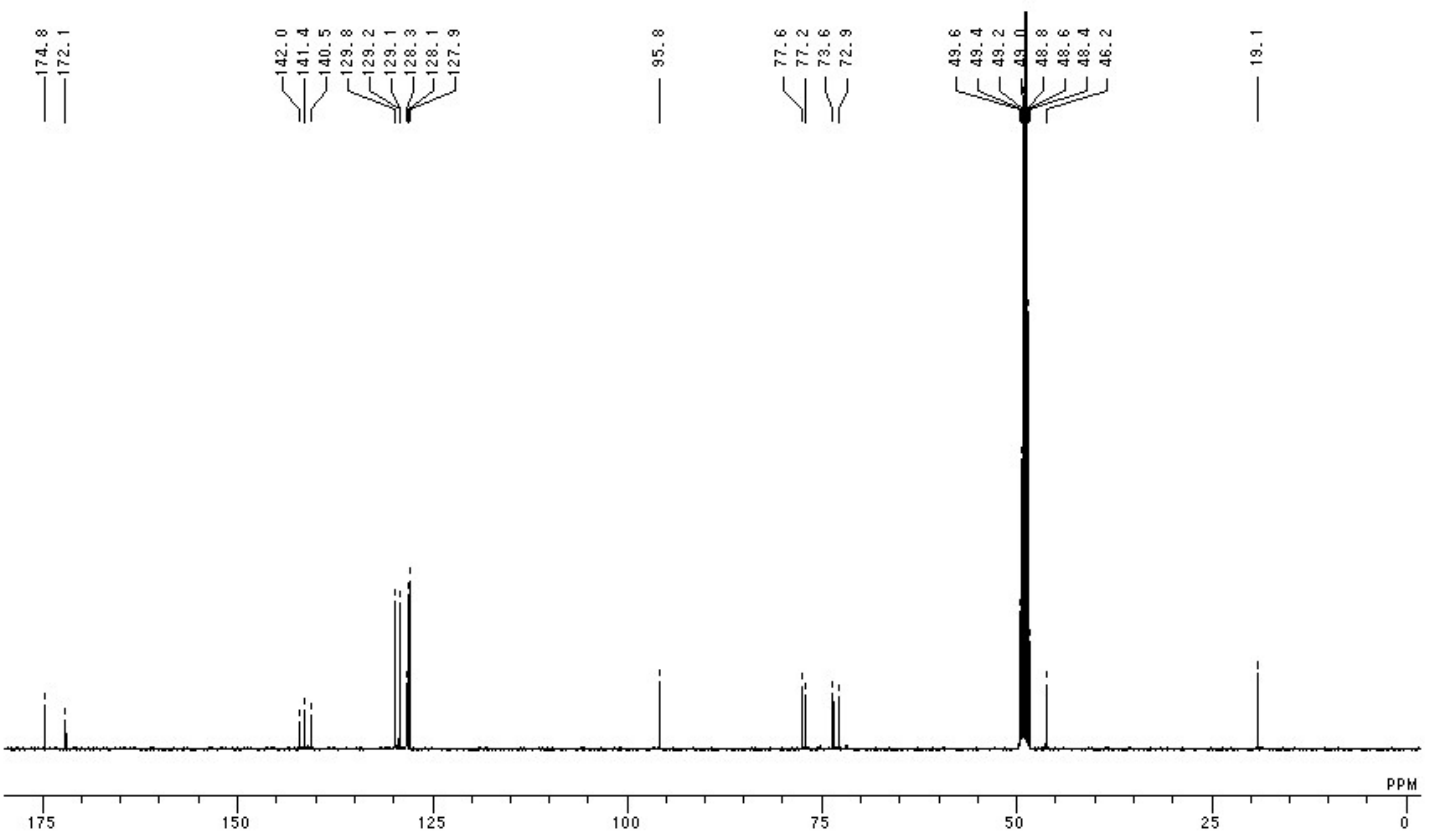




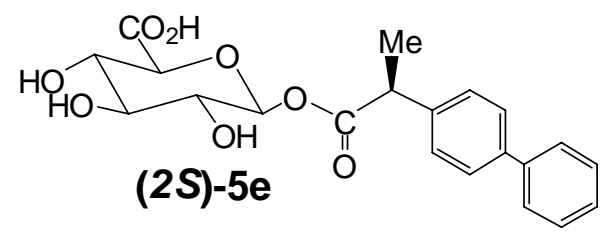

${ }^{1}$ H NMR

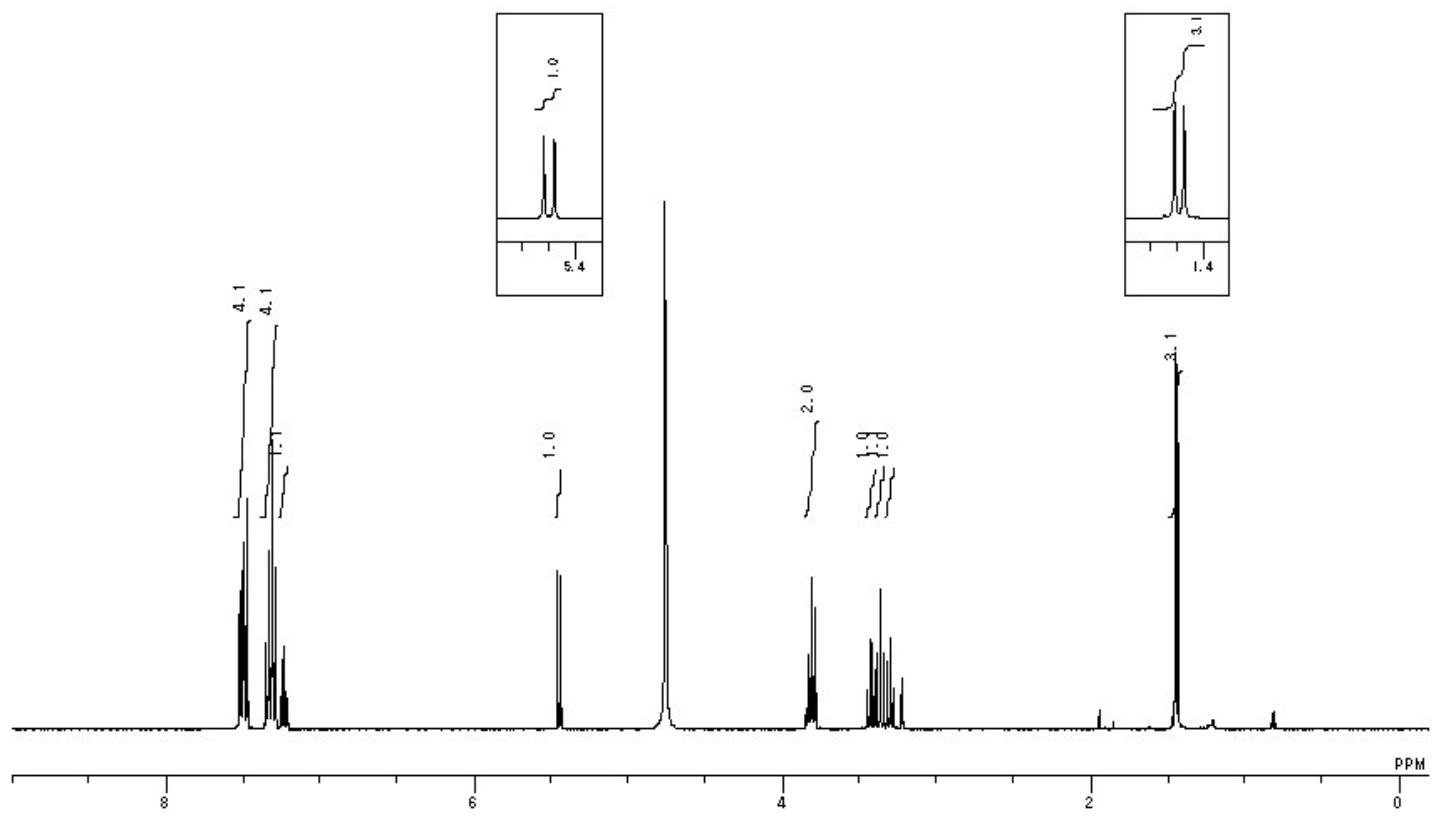

${ }^{13} \mathrm{C}$ NMR

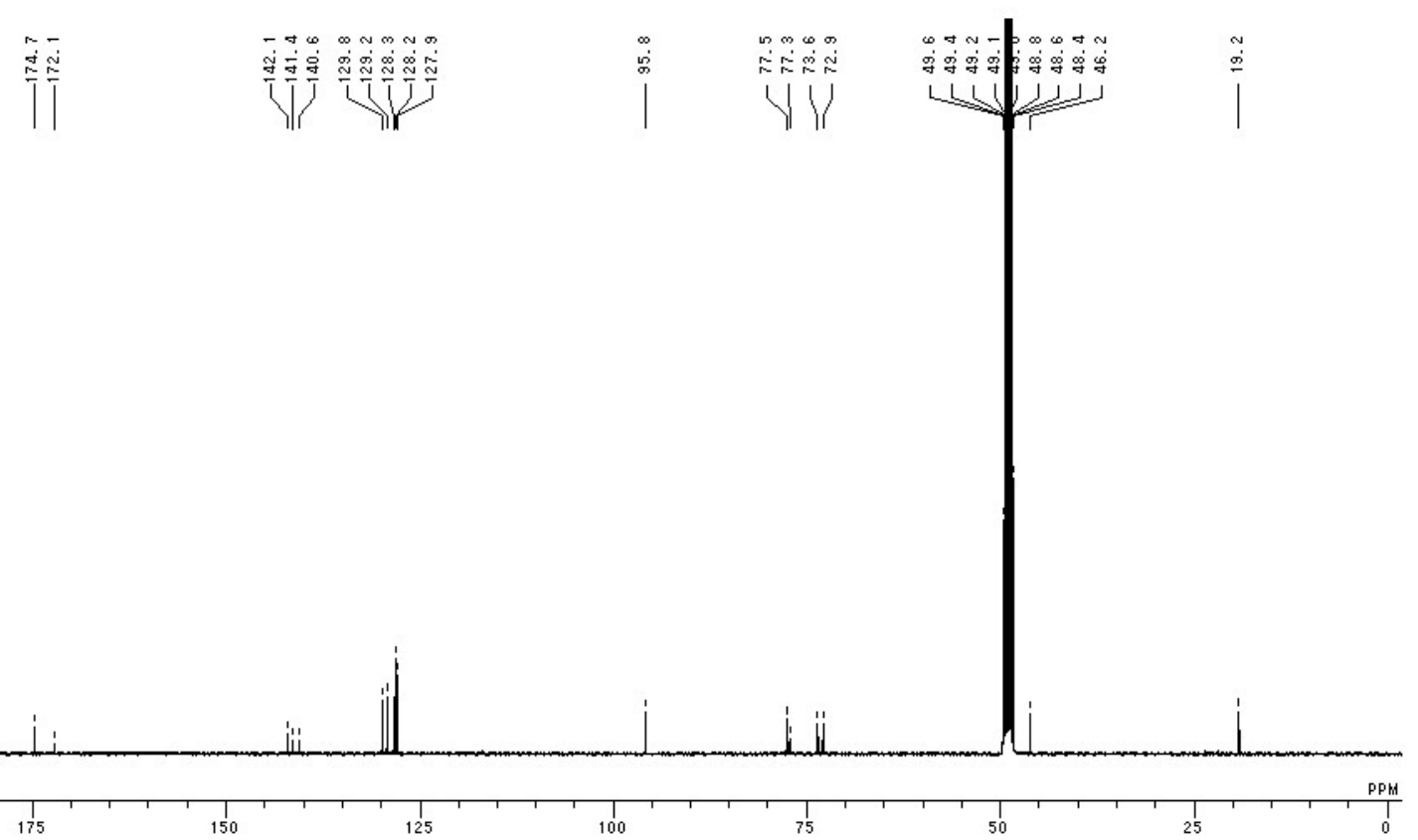




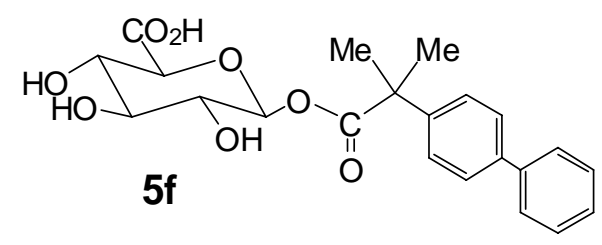

${ }^{1}$ H NMR

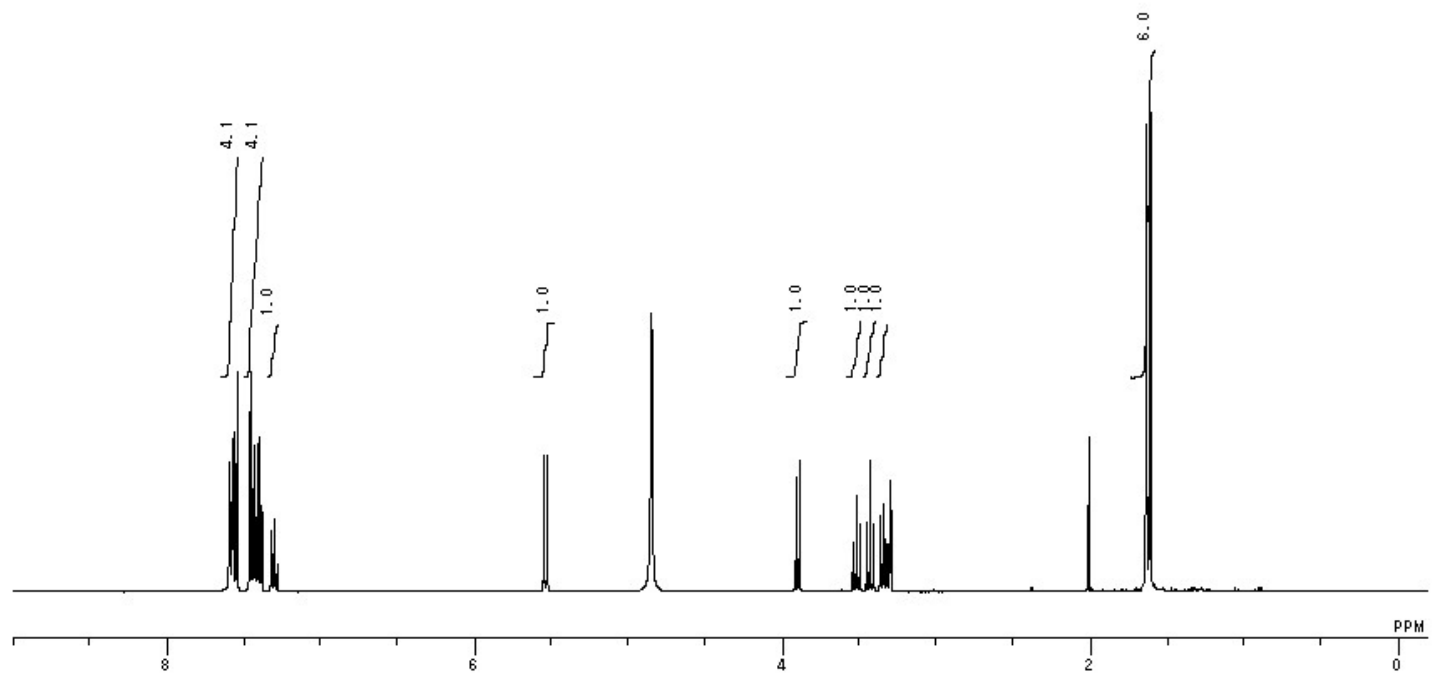

${ }^{13} \mathrm{C}$ NMR

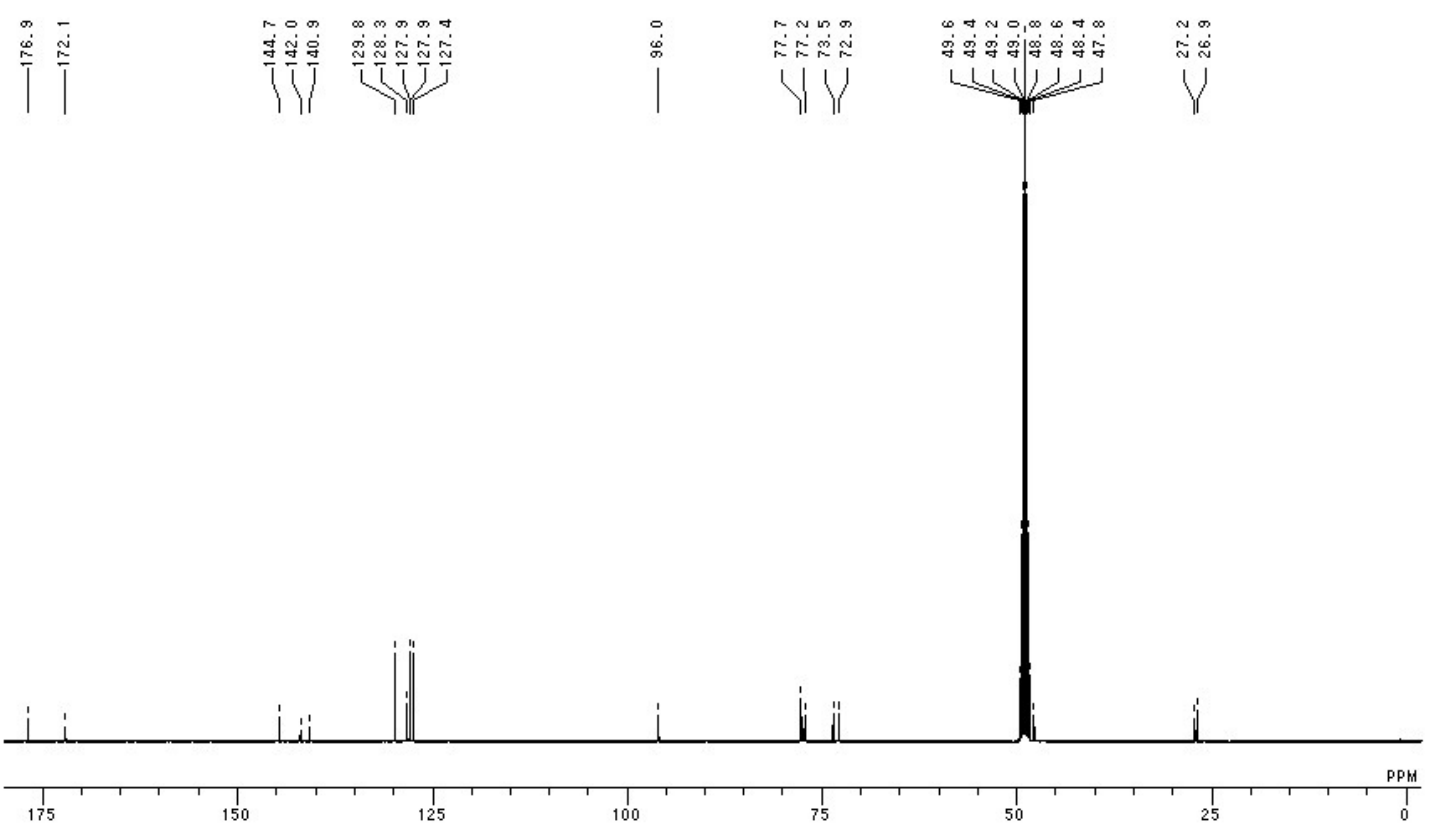




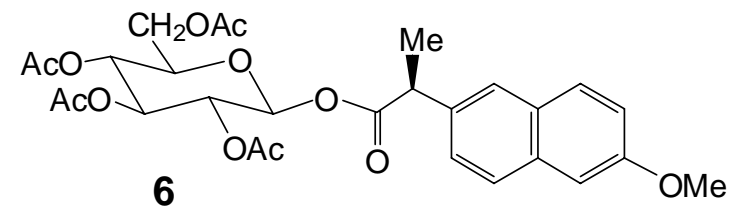

${ }^{1}$ H NMR

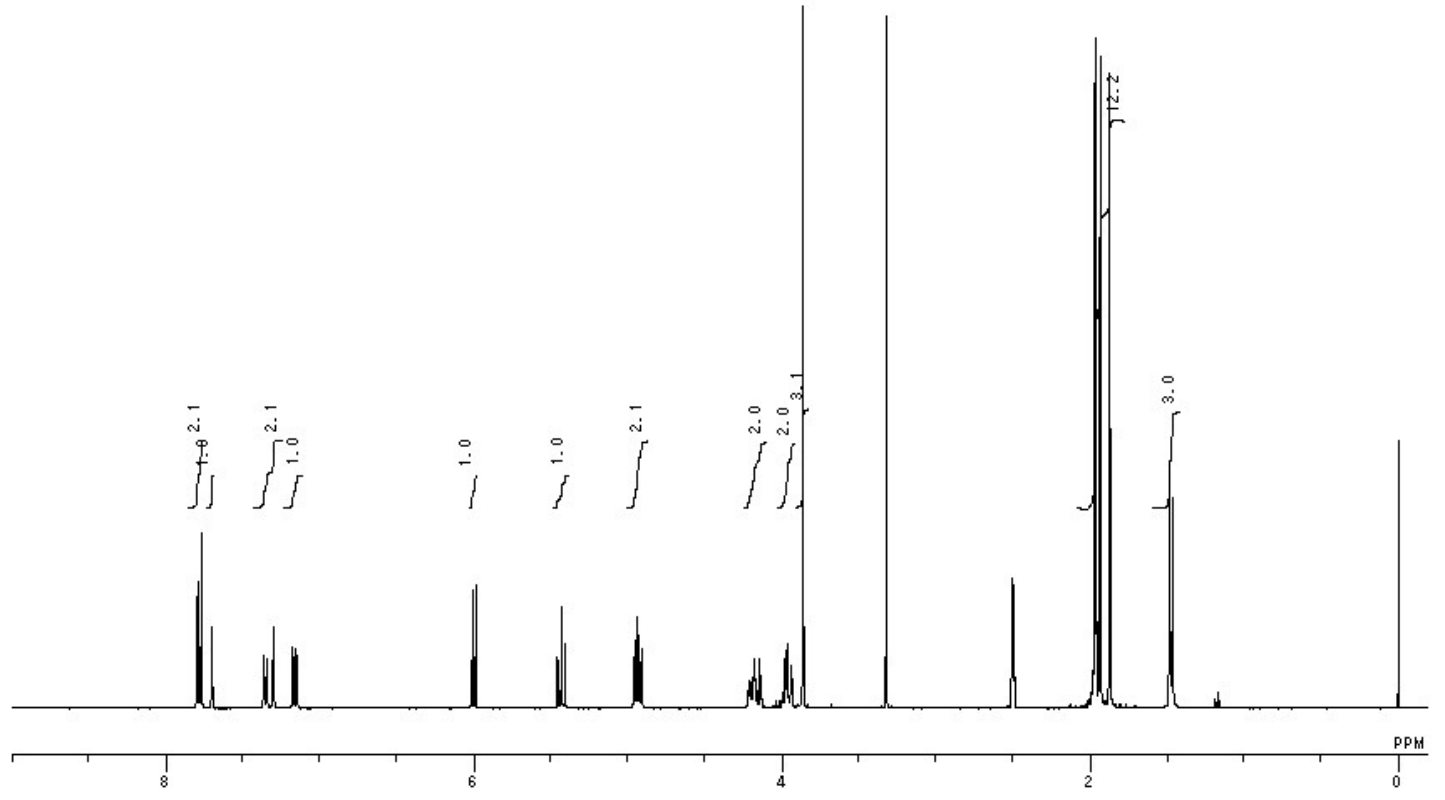

${ }^{13} \mathrm{C}$ NMR

|

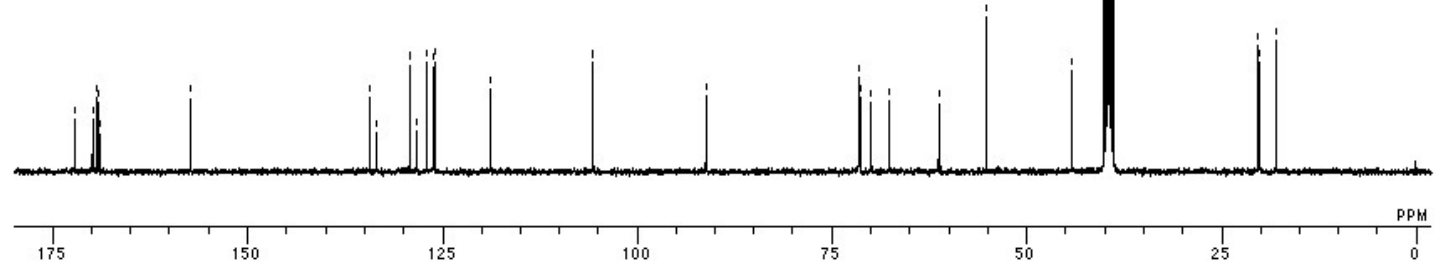




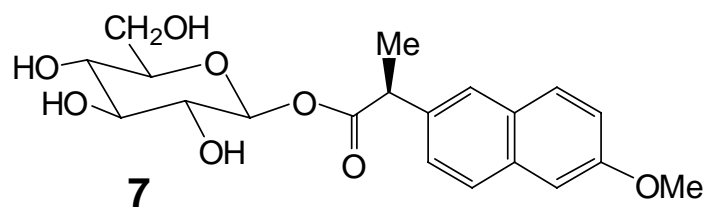

${ }^{1}$ H NMR

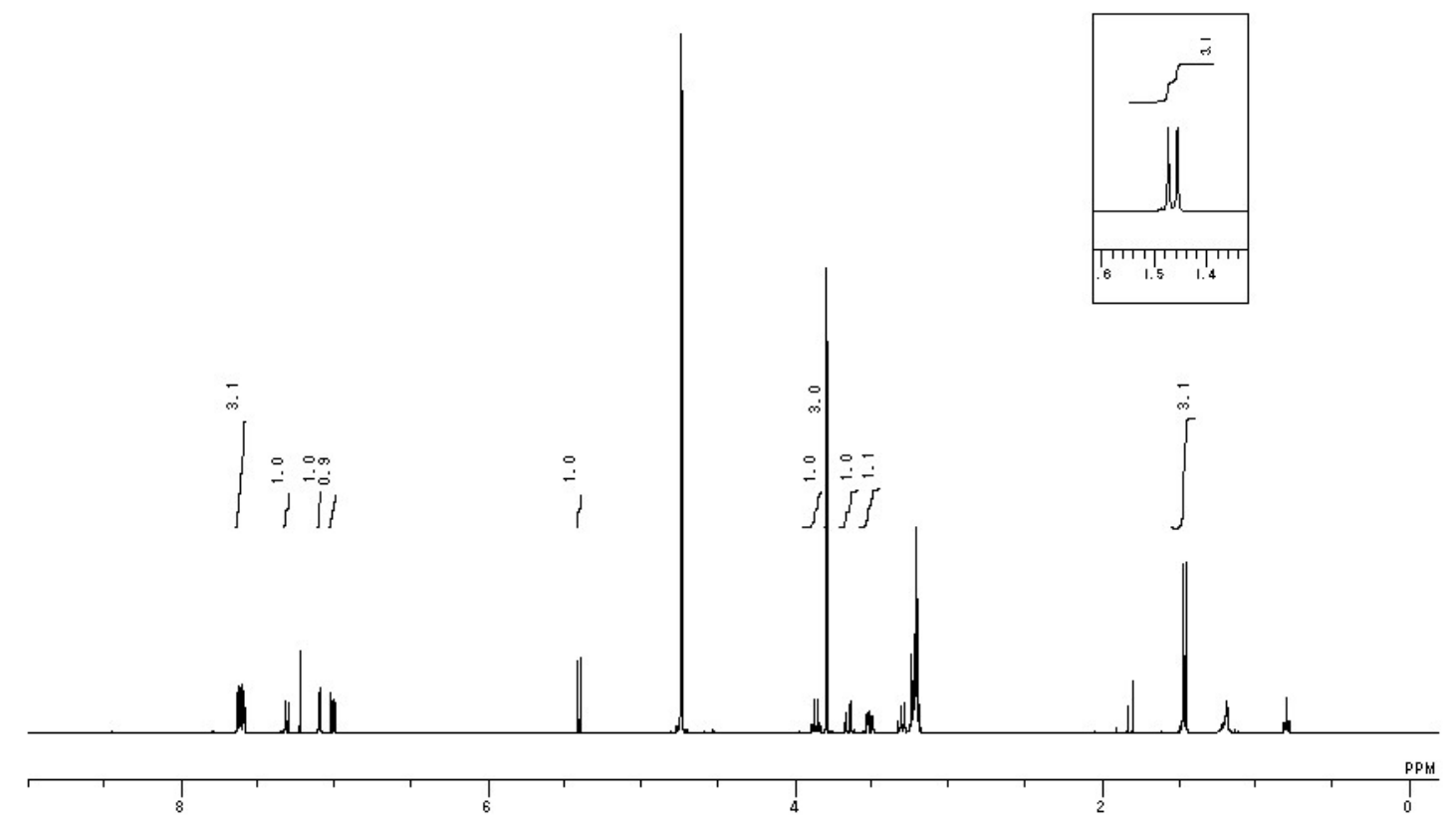

${ }^{13} \mathrm{C}$ NMR

|

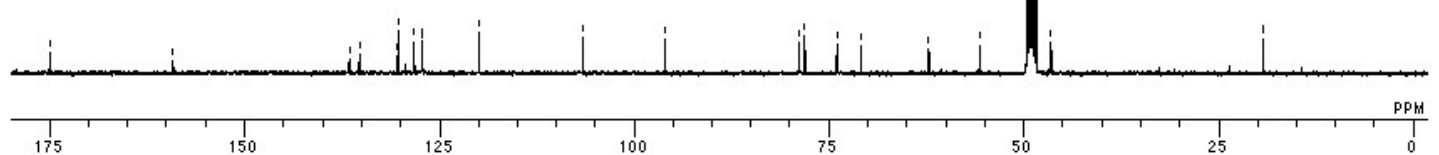

